\title{
Schengen-pathway controls spatially separated and chemically distinct lignin deposition in the endodermis.
}

3 Guilhem Reyt ${ }^{\mathrm{a}}$, Priya Ramakrishna ${ }^{\mathrm{a},{ }^{\dagger}}$, Isai Salas-González ${ }^{\mathrm{b}}$, Satoshi Fujita ${ }^{\mathrm{c},},{ }^{\dagger}$, Ashley

4 Love $^{\mathrm{d}}$, David Tiemessen ${ }^{\mathrm{d}}$, Catherine Lapierre ${ }^{\mathrm{e}}$, Kris Morreel ${ }^{\mathrm{f}, \mathrm{g}}$, Monica Calvo

5 Polanco $^{\mathrm{h}, \boldsymbol{f l}}$, Paulina Flis ${ }^{\mathrm{a}}$, Niko Geldner ${ }^{\mathrm{c}}$, Yann Boursiac ${ }^{\mathrm{h}}$, Wout Boerjan ${ }^{\mathrm{f}, \mathrm{g}}$, Michael W.

6 George $^{\text {d,i }}$, Gabriel Castrillo ${ }^{\text {a }}$, David E. Salt ${ }^{\mathrm{a}, *}$

$7 \quad{ }^{a}$ Future Food Beacon of Excellence \& School of Biosciences, University of Nottingham, Nottingham,

8 LE12 5RD, UK

$9{ }^{b}$ Dept. of Biology CB \#3280 The University of North Carolina at Chapel Hill, North Carolina 27599, USA

$10{ }^{c}$ Department of Plant Molecular Biology, Biophore, University of Lausanne, Lausanne, Switzerland

$11{ }^{d}$ School of Chemistry, University of Nottingham, University Park, Nottingham NG7 2RD, UK

$12{ }^{e}$ Institut Jean-Pierre Bourgin, INRAE, AgroParisTech, Université Paris-Sacla, 78000, Versailles, France

$13{ }^{f}$ Department of Plant Biotechnology and Bioinformatics, Ghent University, B-9052 Ghent, Belgium

$14{ }^{g}$ Center for Plant Systems Biology, VIB, B-9052 Ghent, Belgium

$15{ }^{h}$ Biochimie \& Physiologie Moléculaire des Plantes, University of Montpellier, CNRS, INRA, SupAgro,

1634060 Montpellier, France

$17{ }^{i}$ Department of Chemical and Environmental Engineering, The University of Nottingham Ningbo China,

18199 Taikang East Road, Ningbo 315100, China

19

20

21

22

Present address:

${ }^{\dagger}$ Department of Botany and Plant Biology, University of Geneva, 30 Quai Ernest Ansermet, 1211 Geneva, Switzerland

* National Institute of Genetics, Mishima, Shizuoka, Japan

"Excellence Unit of the University of Salamanca, CIALE, 37185, Salamanca, Spain 


\section{ABSTRACT}

31 Lignin is a complex polymer precisely deposited in the cell wall of specialised plant cells,

32 where it provides essential cellular functions. Plants coordinate timing, location, abundance

33 and composition of lignin deposition in response to endogenous and exogenous cues. In roots,

34 a fine band of lignin, the Casparian strip encircles endodermal cells. This forms an extracellular

35 barrier to solutes and water and plays a critical role in maintaining nutrient homeostasis. A

36 signalling pathway senses the integrity of this diffusion barrier and can induce over-

37 lignification to compensate for barrier defects. Here, we report that activation of this

38 endodermal sensing mechanism triggers a transcriptional reprogramming strongly inducing the

39 phenylpropanoid pathway and immune signaling. This leads to deposition of compensatory

40 lignin that is chemically distinct from Casparian strip lignin. We also report that a complete

41 loss of endodermal lignification drastically impacts mineral nutrients homeostasis and plant

42 growth. 


\section{INTRODUCTION}

Lignin is a phenolic polymer and is one of the main components of secondary-thickened cell wall in vascular plants. Its chemical properties give strength, stiffness and hydrophobicity to the cell wall. Lignin provides mechanical support, modulates the transport of water and solutes through the vascular systems, and provides protection against pathogens $(1,2)$. Lignin polymerisation occurs through oxidative coupling of monolignols and other aromatic monomers $(3,4)$. The monolignols, that is p-coumaryl, coniferyl, and sinapyl alcohols are synthesized from the amino acid phenylalanine through the phenylpropanoid pathway. They are then polymerised into lignin to form the $p$-hydroxyphenyl $(\mathrm{H})$, guaiacyl $(\mathrm{G})$, and syringyl (S) subunits of the lignin polymer. Lignin composition and abundance are highly variable among and within plants species, tissues, cell types and can be modulated by environmental cues (1).

In roots, large amounts of lignin is deposited in the xylem vessels, an important component of the vascular system $(5,6)$. Yet, lignin is also deposited in the endodermal cells surrounding the vascular tissues, for Casparian strip (CS) formation (7). Both the vascular system and the CS play a critical role for water and mineral nutrient uptake from the soil and their transport toward the shoot (8-10). In Arabidopsis thaliana, the composition of lignin monomers in CS and xylem is similar with a strong predominance of G-unit (>90\%) (7). However, the machinery required for CS lignification appears to be distinct from that needed for xylem lignification $(6,11)$.

The deposition of the CS in the endodermal cell wall prevents the apoplastic diffusion of solutes between the outer and inner tissues of the root, forcing solutes to pass through the symplast of endodermal cells (8). CS lignin encircles each endodermal cell, forming a bridge between them. This precise lignin deposition is defined by the presence of the transmembrane Casparian strip domain proteins (CASPs) $(12)$, peroxidases $(13,14)$ and the dirigent-like protein ESB1 (15). The expression of this lignin polymerisation machinery is tightly controlled by the transcription factor MYB36 $(16,17)$. A surveillance mechanism for CS integrity, called the Schengenpathway, boosts CS deposition and is necessary for CS fusion and sealing of the extracellular space (apoplast) (18). This pathway involves vasculature-derived peptides CASPARIAN STRIP INTEGRITY FACTORS 1 and 2 (CIF1 and 2) $(19,20)$ and their perception by the leucine-rich repeat receptor-like kinase (LRR-RLK) called SCHENGEN3 (SGN3, also called GSO1). Their interaction triggers a cascade of signalling events mediated by kinases, that involves SGN1, and the activation of the NADPH oxidase RBOHF (SGN4) leading to ROS production, necessary for lignin polymerisation $(14,18,21)$. These kinase signalling events 
occur on the cortex-facing side of the CS and mediates the transition from a discontinuous CS with islands of lignin into a continuous CS with its characteristic ring of lignin that seals the apoplast (18). Once the CS is sealed, CIF peptide diffusion is blocked and the Schengenpathway becomes inactive. In mutants with an impaired CS, such as esbl and myb36, the Schengen-pathway is constitutively activated due to a constant leak of the CIF(s) peptides through the CS region $(12,15,17,18,22)$. This induces a compensatory lignification in the cell corners and suberisation of endodermal cells. However, the role of this compensatory lignin and the mechanism controlling its deposition are not fully understood.

Here, we demonstrate that the constitutive activation of the Schengen-pathway induces the deposition of a compensatory lignin in the corners of endodermal cells chemically distinct from CS lignin. We characterised this lignin and found commonalities with stress- and pathogenresponse lignin, which has a high content of $\mathrm{H}$ subunit. Furthermore, we demonstrate that this cell corner lignification is preceded by a transcriptional reprogramming of endodermal cells, causing a strong induction of the phenylpropanoid pathway and a significant inactivation of aquaporin expression. Our findings also establish that the activation of the Schengen-pathway to compensate for a defective CS is of critical importance for plants to maintain their mineral nutrients homeostasis and water balance.

\section{RESULTS AND DISCUSSION}

\section{SGN3 and MYB36 control two pathways leading to different endodermal lignification.}

In order to disentangle the role of MYB36 and SGN3 in controlling endodermal lignification, we generated the double mutant sgn3-3 myb36-2. We analysed the endodermal accumulation of lignin in the double mutant sgn3-3 myb36-2, and the corresponding single mutants sgn3-3 and myb36-2 (Fig. 1A-C). In the early stage of endodermal differentiation, we observed deposition of CS lignin in "a string of pearl" manner in WT and sgn3-3 (Fig. 1A). No endodermal lignification was observed in myb36-2 or sgn3-3 myb36-2 at this developmental stage of the root (Fig. 1A). Later in endodermal development, 10 cells after the onset of elongation, we observed a continuous CS ring of lignin, sealing the endodermal cells in WT plants (Fig. 1A-C). As we expected, in sgn3-3 impaired in the activation of the Schengenpathway, CS lignification still appears in a discontinuous fashion, and myb36-2 exhibits compensatory lignification in the corners of the endodermal cells facing the cortical side of the endodermis as previously reported $(9,17)$. In contrast, no ectopic lignification was observed in the double mutant sgn3-3 myb36-2 at the same developmental stage (Fig. 1A-C). These results 
113 establish that the cell-corner compensatory lignification observed in myb36-2 lacking CS (17),

114 is SGN3-dependent.

115 To test how these different patterns of endodermal lignification found in WT, sgn3-3, myb36-

1162 and sgn3-3 myb36-2 affect the permeability of the root apoplast, we assessed the penetration

117 of the fluorescent apoplastic tracer propidium iodide (PI) (23) into the stele (Fig. 1D). We

118 quantified the percentage of root length permeable to PI, and found that it is partially increased

119 in sgn3-3 and myb36-2 in comparison with WT (Fig. 1D). Surprisingly, we observed in the

120 double mutant sgn3-3 myb36-2, that the entire length of the root was permeable to PI, indicating

121 an additive effect of both mutations in the double mutant. This result suggests that MYB36 and

122 SGN3 control endodermal lignification through two-independent pathways. The lack of

123 compensatory cell-corner lignification in sgn3-3 myb36-2 could explain the full permeability

124 of the root found in these plants. This finding supports recent observations assigning a role as

125 an apoplastic barrier to the SGN3-dependent cell-corner lignification (13). In addition, over-

126 activation of the Schengen-pathway is also known to trigger an enhanced suberisation in other

127 CS mutants, including myb36 $(9,17,24)$. We confirm this observation in the myb36-2 mutant

128 where an early suberisation is observed (Fig. 1E). This enhanced suberisation in myb36 is also

129 SGN3 dependent since the sgn3-3 myb36-2 double mutant shows the same pattern of

130 suberisation as WT plants (Fig 1E).

131 Our results indicate that MYB36 and SGN3 control endodermal lignification through two 132 pathways: (a) The pathway involved in CS lignification controlled by both MYB36 and SGN3;

133 and (b) The pathway involved in compensatory lignification of the endodermal cell corners 134 controlled exclusively by SGN3.

\section{Endodermal cell-corner lignin is chemically distinct from CS lignin}

137 We investigated the chemical nature and biochemical origins of CS lignin and compensatory 138 cell-corner lignin. For this, we used confocal Raman microscopy on root cross-sections, in 139 order to spatially resolve the chemistry of these different types of lignin. We triggered 140 endodermal cell-corner lignin deposition by feeding WT plants with CIF2 peptide (+CIF2), the 141 ligand of the SGN3 receptor, able to activate the Schengen-pathway. We separately imaged 142 regions of interest (ROIs) containing CS lignin in WT plants, ROIs with endodermal cell143 corner lignin in WT treated with CIF2 and ROIs containing xylem lignin from WT plants, 144 treated or not with CIF2 (Sup. Fig. 1). Then, we used a multivariate curve resolution (MCR) 145 analysis on these Raman images to spatially and spectrally resolve lignin in these different 146 ROI. The lignin spectra corresponding to these regions are shown in Fig. 2A-B. We observed 
that the CS lignin spectrum is distinct from that of endodermal cell-corner lignin. For example,

148 peaks known to be assigned to lignin display higher (ex: $1337 \mathrm{~cm}^{-1}$, aliphatic $\mathrm{OH}$ bend (25))

149 and lower (ex: $1606 \mathrm{~cm}^{-1}$, aromatic ring stretch (25)) intensity in CS lignin in comparison with

150 endodermal cell-corner lignin. Another striking difference was observed for the peak at 1656-

$1511659 \mathrm{~cm}^{-1}$ assigned to a double bond conjugated to an aromatic ring (e.g.: coniferyl alcohol or

152 coniferaldehyde, (25)). This peak is missing in the endodermal cell-corner lignin of WT treated

153 with CIF2 in comparison with CS lignin, suggesting a change in the phenolic composition of

154 the cell-corner lignin. Conversely, the xylem lignin spectrum of plants treated with or without

155 CIF2 was similar, with the most intense peaks showing comparable intensity. This suggests

156 that changes in lignin composition triggered by the over-activation of the Schengen-pathway

157 mainly occur in the endodermis, and xylem lignin remains largely unaffected.

158 These conclusions were further confirmed spatially by mapping the intensity of these different

159 lignin spectra on large Raman maps containing xylem and endodermal lignin in WT plants

160 treated or not treated with CIF2 (Fig. 2C). We observed that the CS lignin spectrum localises

161 to the CS and xylem vessels suggesting a similar lignin composition, as previously shown for

162 monomer composition using thioacidolysis (7). Additionally, the endodermal cell-corner lignin

163 spectrum localises almost exclusively to the site of lignification in the corners of the

164 endodermal cells, and is essentially absent from the xylem. However, the xylem lignin

165 spectrum (WT +CIF2) matches exclusively to the xylem vessel and is not observed at the

166 endodermal cell corners. This strongly supports the conclusion that over-activation of the

167 Schengen-pathway triggers deposition of lignin at endodermal cell-corners that has a unique

168 chemical composition compared to both CS and xylem lignin.

169 To confirm these differences between CS and endodermal cell-corners lignin, we adopted an

170 approach to directly measure the subunit composition of endodermal lignin avoiding possible

171 contamination from the highly lignified protoxylem cells (7). We genetically crossed a

172 collection of CS mutants that represent different level of lignin accumulation in the endodermis

173 with the arabidopsis histidine transfer protein 6.1 mutant (ahp6-1). This mutant, in the 174 presence of low amounts of the phytohormone cytokinin, shows a strong delay in protoxylem 175 differentiation, without affecting CS formation (Fig. 2D) (7, 26). Therefore, in the resulting

176 lines the majority of lignin derived from the protoxylem is lost allowing us to analyse primarily

177 lignin with an endodermal origin. To explore how the chemical composition of the cell-corner 178 lignin differs from CS lignin, we collected root tips (3 mm) of 6-day-old ahp6-1 and ahp6-1 179 esb1-1 sgn3-3 mutants accumulating CS lignin only, and from mutants (ahp6-1 myb36-2 and 180 ahp6-1 esb1-1) with cell-corner lignification and a reduced amount of CS lignin. Additionally, 
181 as a control we used ahp6-1 plants treated with the CIF2 peptide that strongly induces the

182 Schengen-pathway and deposition of cell-corner lignin (Fig. 2D). We measured the relative

183 content of H, G and S subunits in lignin in all samples using thioacidolysis followed by GC-

184 MS (Fig. 2E). We found that CS lignin monomer composition in our control line ahp6-1 (H:

$1855 \%$, G: 87\%, S: 8\%) was similar to that previously reported (7). The monomer composition of

186 the defective CS in the mutant ahp6-1 esb1-1 sgn3-3 is overall similar to WT with a small

187 increase in $\mathrm{G}$ and decrease in S subunits. Strikingly, we observed that lignin composition in 188 the lines and treatments that induce the accumulation of cell-corner lignin (ahp6-1 esb1-1,

189 ahp6-1 myb36-2, ahp6-1(+CIF2)) was different from the control and mutant lines that only 190 accumulate lignin in the CS. The lignin extracted from these plants showed a higher proportion 191 of $\mathrm{H}$ monomers. In the case of ahp6-1 treated with CIF2, H content was increased to $19 \%$ and

192 G content was decreased. Thioacidolysis and Raman results indicate that over-activation of the

193 Schengen-pathway triggers the deposition of a chemically distinct H-rich lignin in the corner 194 of the endodermal cells.

195 Such a high content of $\mathrm{H}$ subunits in lignin is rarely found in angiosperm. Similar levels of H 196 subunits in lignin mainly occurs in compression wood of gymnosperm (27-30) and in defence197 induced lignin, and has been termed "stress lignin" (31-35). We therefore conclude that 198 Schengen-pathway induced endodermal cell-corner lignin is a novel form of 'stress lignin'.

199 Taken together, both chemical analysis of lignin subunits by thioacidolysis and spatially resolved confocal Raman spectroscopy show that lignin deposited in endodermal cell corners upon activation of the Schengen-pathway is H-rich and chemically and spatially distinct from both CS and xylem lignin.

Schengen-pathway modulates the phenylpropanoid pathway and induces defense-related mechanisms.

To investigate the biosynthesis of the endodermal H-rich stress lignin we performed RNA-seq on root tips $(5 \mathrm{~mm})$ of WT plants, on roots showing a strong activation of the Schengenpathway (WT treated with exogenous CIF2, myb36-2 and esb1-1) and roots with no Schengen signalling (sgn3-3, esb1-1 sgn3-3, sgn3-3 myb36-2 and sgn3-3 treated with exogenous CIF2). Clustering analysis of the differentially expressed genes shows that roots displaying cell-corner lignification (WT treated with exogenous CIF2, myb36-2 and esb1-1) due to the over-activation

211 of the Schengen-pathway share a similar transcriptional response that is distinct from that 212 observed in the other genotypes (Fig. 3A, Sup. Fig. 2A, Sup. Table 1). CIF2 application to 213 sgn3-3 shows a similar transcriptional response to non-treated WT and sgn3-3 and does not 214 trigger the transcriptional changes observed during the strong activation of the Schengen- 
215 pathway (WT treated with exogenous CIF2, myb36-2 and esb1-1). This is in line with previous 216 transcriptomic data in response to CIF2 (18) and the idea that SGN3 is the only receptor for

217 CIF2 in roots. We observed that genes in cluster $\mathrm{C} 1$ are upregulated by the activation of the

218 Schengen-pathway. This cluster is enriched in genes involved in the phenylpropanoid pathway

219 (Sup. Fig. 2B). We hypothesize that the activation of this pathway would provide the phenolic substrates required for the enhanced lignification and suberisation induced by the Schengenpathway. We observed strong activation of expression of genes encoding all the key enzymes of the phenylpropanoid pathway required for monolignol biosynthesis, with the exception of $C 3^{\prime} H, C 3 H$ and $F 5 H$ (Fig. 3B, Sup. Fig. 2C). H-rich lignin is known to be accumulated when expression of $C 3$ ' $H$ is repressed in $A$. thaliana and poplar (36-39). This activation of all the main enzymes of the phenylpropanoid pathway with the exception of $C 3^{\prime} H$ observed after triggering the Schengen-pathway could explain the high level of H-units incorporation into endodermal cell-corner lignin (Fig. 3B, Sup. Fig. 2C). Similarly, the roots of the cellulose synthase isomer mutant elil (ectopic lignification1) accumulate H-rich lignin and display strong gene activation for most of the phenylpropanoid pathway, with the exception of $C 3$ ' $H$ (40). Interestingly, ectopic lignification in this mutant is also under the control of another receptor-like kinase, THE1 (THESEUS), also involved in cell wall integrity sensing $(41,42)$. We then tried to identify transcriptional regulators with a role in the regulation of the Schengenpathway sector controlling phenylpropanoid synthesis. We performed a gene expression correlation analysis between the phenylpropanoid pathway genes and their transcriptional regulators $(3,43)$ (Sup. Fig. 2C). We found that the expression of the transcription factor MYB15 highly correlates with the expression of most of the genes required for monolignol biosynthesis, with the notable exception of $C 3$ 'H (Sup. Fig. 2C). Upregulation of MYB15 in response to CIF2 have been previously shown (18). This transcription factor is known to bind to the promoter of PAL1, C4H, HCT, CCOAOMT1 and COMT but does not bind to the promoter of $C 3$ ' $H$ and $F 5 H$ (44). Schengen-pathway activation of $M Y B 15$ expression provides a plausible mechanism to explain the induction of the main enzymes of the phenylpropanoid pathway with the exception of $C 3^{\prime} H$ and $F 5 H$. This modulation of gene expression could explain the enhanced incorporation of $p$-coumaryl alcohol into the stress lignin we observe at endodermal cell corners. Interestingly, MYB15 is an activator of basal immunity in A. thaliana by inducing the synthesis of defense lignin and soluble phenolics (44).

To test if over-activation of the Schengen-pathway leads to the production of defense-inducible soluble phenolics, we undertook secondary metabolites profiling using Ultra High Performance 
mutant having a defective CS and constitutive activation of the Schengen-pathway, in sgn3-3 and sgn3-3 esb1-1 having a defective CS and inactivation of the Schengen-pathway and in WT.

251 We observed distinct accumulation of soluble secondary metabolites across the different genotypes (Sup. Fig. 3, Sup. Table 2). We identified 20 phenolic compounds that differentially accumulate specifically due to the activation of the Schengen-pathway out of 52 compounds. We found higher accumulation of the conjugated neolignan $\mathrm{G}(8-\mathrm{O}-4) p \mathrm{CA}$, scopoletin, flavonoid derivatives such as conjugated kaempferol (astragalin and 4'-O-acetylkaemferol-3O-hexoside), isorhamnetin and acetylhyperoside. Scopoletin biosynthesis is controlled by the enzyme F6'H1 and COSY $(45,46)$ and the transcription factor MYB15 (44). We found that the expression of the three genes encoding these proteins is induced by the over-activation of the Schengen-pathway (Fig 3B, Sup. Fig. 2C). Scopoletin is a modulator of plant-microbe interaction $(44,47-49)$. In addition to that, we found a strong induction of genes related to defense (response to chitin/systemic acquired resistance/immune response/hypersensitive response) among the genes induced by the activation of the Schengen-pathway (C1; Fig. 3A and Sup. Fig. 2B). This corroborates a publication showing similarities between the Schengenpathway and the microbe-associated molecular patterns (MAMP) signalling pathway (18).

\section{Cell wall attachment to plasma membrane relies on CS domain formation rather than}

\section{lignin deposition.}

The apoplast in between two endodermal cells is sealed by the deposition of CS lignin. This sealing is perfected by the anchoring of the CS membrane domain (CSD) to the cell wall (CW), through an unknown mechanism. Upon plasmolysis, the protoplasts of endodermal cells retract but the CSD remains tightly attached to the CS $(23,50,51)$. This attachment appears in a developmental manner during the differentiation of the endodermis and occurs in a concomitant manner with the recruitment of the Casparian strip membrane domain proteins (CASPs) at the CSD and with CS lignin deposition (23). We then wanted to study whether or not the different types and sites of lignification contribute to the attachment of the plasma membrane (PM), to the $\mathrm{CW}$. To visualize the PM, we used an endodermis specific PM marker (pELTP::mCit-SYP122) in WT, sgn3-3, myb36-2 and sgn3-3 myb36-2 (Fig. 4A). The PM marker is excluded from the CSD in WT as described for other endodermal plasma membrane marker lines $(14,23)$. This exclusion is still observed in sgn3-3 but in an interrupted manner similarly to that observed for lignin (Fig. 1A-C). The exclusion domain disappears entirely in the myb36-2 and sgn3-3 myb36-2 mutants. Additionally, no exclusion zone in the PM is observed in myb36-2 where cell-corner lignin is deposited. We then used mannitol-induced 
plasmolysis to visualise the PM attachment to the CW. Upon plasmolysis, the PM retracts but remains attached to the CS in WT and sgn3-3, forming a flattened protoplast (Fig. 4A). However, small portions of the PM are able to detach from the $\mathrm{CW}$ in a sgn3-3 mutant as seen in Supp. Fig. 4A. This is likely to happen where the PM exclusion domain is interrupted in sgn3-3 (Fig. 4A). In myb36-2 and sgn3-3 myb36-2, the CW attachment to the PM is lost (Fig. 4A, Supp. Fig. 4A). Importantly, retraction of the PM is observed in myb36-2 at the corner of the endodermal cells on the cortex side where cell-corner lignin is deposited (Fig 1A). These results clearly show the requirement of MYB36 for the formation of the CSD excluding the PM marker. Additionally, the presence of CSD, but not cell-corner lignin is required for PM attachment to the CW.

293 We then tested if CS lignin is required for the PM attachment to the CS. For this, we used an inhibitor of the phenylpropanoid pathway, piperonylic acid (PA), that inhibit lignin accumulation (7). Treatment with PA suppresses lignin accumulation in the vasculature and in the CS (Fig. 4B). Absence of lignin did not affect the exclusion of the PM marker at the CSD. This was further confirmed using the CSD marker line (pCASP1::CASP1-GFP) (12) that showed similar localisation independently of the CS lignin presence (Fig. 4B). Additionally, the PM attachment to the CS is still observed when CS lignin deposition is inhibited (Fig. 4AB, Supp. Fig. 4A). These findings indicate that CS lignin is not required for the formation of the CSD as previously reported $(14,18)$ and importantly that CS lignin does not participate in anchoring the CSD to the $\mathrm{CW}$. Other $\mathrm{CW}$ compounds might be involved in that process. The absence of PM attachment to the site of cell-corner lignification is likely to affect the permeability of the apoplast of the endodermal cells. This can consequently affect the transport of water and solutes to the shoot.

\section{Total absence of an endodermal apoplastic barrier triggers major ionomic changes.}

308 We then investigated how the different types of endodermal lignification control nutrient

309 homeostasis in the plant. The sgn3-3 (delayed CS barrier, no cell-corner lignin), myb36-2 (no

310 CS lignin, has cell-corner lignin) and sgn3-3 myb36-2 (no CS or cell-corner lignin) mutants

311 were grown using different growth conditions (agar plate, hydroponic, and natural soil) and

312 leaves were analysed for their elemental composition (ionome) using inductively coupled-mass 313 spectrometry (ICP-MS; Fig. 5A and Sup. Table 3). A Principal Component Analysis (PCA) of 314 the ionome of leaves reveals that all the mutants have different leaf ionomes compared to WT 315 when grown on plates (Fig. 5B), in hydroponic and to a lesser extent in natural soil (Sup. Fig. 3165 A-B). Based on the PC1 axis, the double mutant sgn3-3 myb36-2 displayed the most distinct 
317 ionomic phenotype (Fig 5B, Sup. Fig 5 A-B). In line with our previous results (Fig. 1D), this

318 effect indicates an additivity of the two mutations on the leaf ionome. Importantly, this result

319 also supports that cell-corner stress lignin in the single mutant myb36 can act as an apoplastic

320 barrier to mineral nutrients.

321 We next tested the correlation between the gradient of root apoplastic permeability across WT, 322 myb36-2, sgn3-3 and sgn3-3 myb36-2 determined in Fig. 1D with their elemental content in 323 leaves (Fig 5C). We observed that the myb36-2 mutant does not fit into this correlation analysis 324 as well as the other genotypes. This is likely due to the activation of the Schengen-pathway 325 leading to the deposition of endodermal cell-corner stress-lignin, early suberisation, reduced 326 root hydraulic conductivity, activation of ABA signalling in the shoot, and stomata closure (9, 327 24). Additionally, the myb36-2 mutation interferes with overall root development (Sup. Fig. 5 328 C-E) as previously reported (52). This is due to the over-activation of the Schengen-pathway as the double sgn3-3 myb36-2 mutant shows normal root development. Removal of myb36-2

330 from the correlation analysis, leaving just lines with an inactive Schengen-pathway, improved the Pearson correlation coefficient for almost all the elements, and we observed a strong correlation $(r \geq 0.5$ or $r \leq-0.5)$ for 15 out of 20 elements. We observed a strong positive correlation between an increased CS permeability and leaf accumulation of lithium (Li), arsenic (As), manganese (Mn), sodium $(\mathrm{Na})$, strontium $(\mathrm{Sr})$, sulphur $(\mathrm{S})$, copper $(\mathrm{Cu})$, calcium $(\mathrm{Ca})$, boron $(\mathrm{B})$, and a strong negative correlation with iron $(\mathrm{Fe})$, cadmium $(\mathrm{Cd})$, phosphorus $(\mathrm{P})$, zinc $(\mathrm{Zn})$, rubidium $(\mathrm{Rb})$ and potassium $(\mathrm{K})$. This suggests that a functional apoplastic barrier is required to limit the loss of essential elements such as $\mathrm{K}, \mathrm{Zn}, \mathrm{Fe}$ and P. Conversely, a defective apoplastic barrier allows increased leaf accumulation of the essential nutrients $\mathrm{Mn}$,

$339 \mathrm{~S}, \mathrm{Cu}, \mathrm{Ca}$, and $\mathrm{B}$. These gradients of higher and lower accumulations of mineral nutrients and 340 trace elements illustrate the bidirectional nature of the CS barrier, by blocking some solutes from entering the vasculature and by facilitating the accumulation of other solutes in the stele for translocation.

Root hydraulic conductivity is reduced by the activation of the Schengen-pathway and it is not affected by the absence of endodermal lignification.

346 We then measured the capacity of the root to transport water, also called root hydraulic conductivity $\left(\mathrm{L}_{\mathrm{r}}\right)$, in 3-week-old plants grown hydroponically. We observed that the root hydraulic conductivity remains unchanged in the mutants sgn3-3 and sgn3-3 myb36-2 in comparison with WT (Fig. 6A). In contrast, the myb36-2 mutant showed a strong reduction of root hydraulic conductivity. These results established that the CS-based endodermal apoplastic 
seal does not control root water transport capacity, as in the absence of any barriers in sgn3-3 myb36-2 (Fig. 1D) root hydraulic conductivity is the same as WT. This is consistent with water transport occurring mainly via the transcellular pathway, with a major contribution via aquaporins (53). The reduced hydraulic conductivity observed in myb36-2 is consistent with that previously observed in esbl which also has an activated Schengen-pathway (24). The reduced hydraulic conductivity in esbl originates mainly from a reduction in aquaporinmediated water transport as determined using an pharmacological approach (24). Here, our RNA-seq experiment revealed a GO-term enrichment in cluster C2 (genes repressed by the Schengen-pathway, Fig. 3A) relating to water deprivation (Sup Fig 3B) and importantly, 10 aquaporin genes are down regulated by activation of the Schengen-pathway (Fig 6B). This set of aquaporin genes contains several highly expressed aquaporins in root, including PIP2,2 known to significantly contribute to root hydraulic conductivity $(54,55)$. This would provide an explanation for the reduction in root hydraulic conductivity observed in both myb36 and esbl.

\section{Endodermal lignification is required for plant growth and survival in low humidity.}

Given the significant impacts that CS and Schengen-pathway activation have on mineral nutrient homeostasis (Fig. 5) and water transport (Fig. 6A-B), we further investigated their impact on growth and development. The double mutant sgn3-3 myb36-2 displayed a severe dwarf phenotype when grown hydroponically or in natural soil but not on agar plates in comparison with WT and the single mutants (Supp. Fig. 5 C-G). This indicates a critical role of CS for maintaining normal plant growth and development. However, this is conditioned by the growth environment. The high humidity environment and consequently reduced transpiration of plants on agar plates in comparison with the other growth environments could explain these phenotypical differences. Indeed, reduced leaf transpiration is a key part of the compensation mechanisms mitigating the loss of CS integrity allowing relatively normal growth as reported in (24). We then tested if differences in relative humidity (RH) can affect plant growth in the absence of an endodermal root barrier. For this, we used sgn3-3 (delayed CS barrier, no cell-corner lignin), myb36-2 (no CS lignin, has cell-corner lignin) and sgn3-3 myb36-2 (no CS or cell-corner lignin). Additionally, we tested if the presence of endodermal suberin can affect plant growth by using lines expressing the Cutinase DEstruction Factor (CDEF) under the control of an endodermis specific promoter (pELTP::CDEF) in a WT and sgn3-3 myb36-2 background and showing a strong reduction of endodermal suberin deposition 
for 7 days and transferred to an environment with the same $(80 \% \mathrm{RH})$ or lower $(60 \% \mathrm{RH})$ humidity. We measured the leaf surface area as a proxy of plant growth (56) at $0,2,5$ and 8 days after transfer (Fig. 6C and Supp. Fig. 6B). In a high and low humidity environment, all mutants with reduced CS functionality (sgn3-3, myb36-2, sgn3-3 myb36-2 and sgn3-3 myb362-pELTP::CDEF) show a reduction of leaf surface in comparison with WT. Importantly, the growth reduction observed in the absence of endodermal lignification (sgn3-3 myb36-2) is severe, specifically in low humidity conditions, in comparison with all other genotypes and high humidity conditions. The sgn3-3 myb36-2 plants with no growth after 9 days started to display necrosis over all the leave surface and were considered dead as quantified in Fig. 6D. Low humidity triggers a high percentage of mortality in sgn3-3 myb36-2 and to a lesser extent in sgn3-3 compared to WT and to the other genotypes in which no mortality is observed when grown in low humidity conditions. Such mortality was not observed if sgn3-3 myb36-2 was grown in high humidity. This highlights that endodermal lignification is required for maintaining plant growth and survival under low humidity. However, this is not the case for endodermal suberisation because the removal of suberin by expressing CDEF in WT and sgn33 myb36-2 did not affect mortality and leaf surface area after 8 days at a lower humidity in comparison with their respective backgrounds (Fig.6 C,D, Supp. Fig. 6B).

The strong growth reduction observed in sgn3-3 myb36-2 in comparison with WT and the single mutants could be associated with the lack of root selectivity leading to major ionomic changes as shown in Fig. 5. The low humidity would generate a higher transpiration stream and consequently leads to a more uncontrolled and detrimental accumulation of mineral nutrient and trace elements in the leaves in comparison with high humidity. Alternatively, a high humidity environment would slow the transpiration rate, allowing plants to better control nutrient acquisition (24).

We then measured the impact of the absence of CS, suberin or of the constitutive activation of the Schengen-pathway on plant fitness. For this, we determined the number of seed-containing siliques per plant as an estimation of fitness (Fig. 6E). A significant reduction of silique numbers is observed in all the genotypes in comparison to WT with the exception of

$413 p E L T P:: C D E F$. The mutant sgn3-3 displaying partial root apoplastic barrier defects showed a 414 decrease in siliques number in comparison with WT. A similar decrease was observed for 415 myb36-2 displaying also a partial root apoplastic barrier defect with cell-corner stress lignin 416 deposition. Complete disruption of endodermal lignification strongly affects silique production 417 as observed for sgn3-3 myb36-2 and sgn3-3 myb36-2 - pELTP::CDEF. These results establish 418 that the CS is essential for plant fitness. Further, activation of the Schengen-pathway helps 
419 protect the plant from this detrimental impact on fitness when the barrier function of the CS is 420 compromised. The sgn3-3 myb36-2 - pELTP::CDEF line reported here, with it complete lack

421 of endodermal lignin and suberin extracellular barriers and Schengen-dependent signaling, is

422 a powerful tool for studying the role of endodermal barriers in a range of processes such as

423 nutrient, hormone and water transport and biotic interaction with soil microorganisms.

425 The data presented here revealed that the Schengen-pathway is involved in the deposition of 426 two chemically distinct types of lignin. The Schengen-pathway with MYB36 are required for 427 the deposition of CS lignin. Constitutive activation of the Schengen-pathway leads to the 428 deposition of a chemically distinct stress-like type of lignin. This deposition of stress-lignin 429 contributes to sealing the apoplast maintaining ion homeostasis in the absence of CS integrity. 430 However, no PM attachment to the $\mathrm{CW}$ is observed at the site of stress-lignin deposition as 431 seen for the CS, suggesting an inferior seal is formed.

\section{MATERIALS \& METHODS}

\section{Plant material}

436 Arabidopsis thaliana accession Columbia-0 (Col-0) was used for this study. The following 437 mutants and transgenic lines were used in this study: sgn3-3 (SALK_043282) (9), myb36-2 438 (GK-543B11) (17), pCASP1::CASP1-GFP (12), ahp6-1 (26), esb1-1 (10), pELTP::CDEF(57), 439 pELTP::SYP122-mCitrine.

440 The corresponding gene numbers are: SGN3, At4g20140; MYB36, At5g57620; CASP1, 441 At2g36100; AHP6, At1g80100; ESB1, At2g28670; ELTP, At2g48140; CDEF, At4g30140; 442 SYP122, At3g52400.

\section{Generation of transgenic lines}

445 The pELTP::mCit-SYP122 construct was obtained by recombining three previously generated 446 entry clones for pELTP(58), mCITRINE and SYP122 cDNA(59) using LR clonase II 447 (Invitrogen). This construct was independently transformed into WT, sgn3-3, myb36-2, or 448 sgn3-3 myb36-2 using the floral dip method (60).

\section{Growth Conditions}

451 For agar plates assays, seeds were surface sterilized, sown on plates containing $1 / 2$ MS 452 (Murashige and Skoog) with $0.8 \%$ agar, stratified for two days at $4{ }^{\circ} \mathrm{C}$ and grown vertically in 
growth chamber under long day condition $\left(16 \mathrm{~h}\right.$ light $100 \mu \mathrm{E} 22^{\circ} \mathrm{C} / 8 \mathrm{~h}$ dark $\left.19^{\circ} \mathrm{C}\right)$ and observed

454 after 6 days. Piperonylic acid was used from germination at $10 \mu \mathrm{M}$ as described in (7). The

455 CIF2 peptide treatment (DY(SO3H)GHSSPKPKLVRPPFKLIPN) were applied from

456 germination at a concentration of $100 \mathrm{nM}$. The CIF2 peptide was synthetized by Cambridge

457 Peptided Ltd.

458 For ionomic analysis, plants were grown using three growth conditions:

459 - Sterile $1 / 2$ MS agar plate. Seeds were surface sterilized and sown on plates containing $1 / 2$ MS

460 (Murashige and Skoog) with $0.8 \%$ agar, stratified for two days at $4{ }^{\circ} \mathrm{C}$ and grown vertically in

461 growth chamber under long day condition (16h light $100 \mu \mathrm{E} 22^{\circ} \mathrm{C} / 8 \mathrm{~h}$ dark $\left.19^{\circ} \mathrm{C}\right)$. Shoots were

462 collected two weeks after germination.

463 - Hydroponic. Plants were grown for 5 weeks under short day condition (8h light $100 \mu \mathrm{E}$

$46421^{\circ} \mathrm{C} / 16 \mathrm{~h}$ dark $18^{\circ} \mathrm{C}$ ) at $20^{\circ} \mathrm{C}$ with a relative humidity of $65 \% \mathrm{RH}$ in a media at pH 5.7

465 containing $250 \mu \mathrm{M} \mathrm{CaCl}_{2}, 1 \mathrm{mM} \mathrm{KH}_{2} \mathrm{PO}_{4}, 50 \mu \mathrm{M} \mathrm{KCl}, 250 \mu \mathrm{M} \mathrm{K}_{2} \mathrm{SO}_{4}, 1 \mathrm{mM} \mathrm{MgSO}, 100$

$466 \mu \mathrm{M}$ NaFe-EDTA, $2 \mathrm{mM} \mathrm{NH}_{4} \mathrm{NO}_{3}, 30 \mu \mathrm{M} \mathrm{H}_{3} \mathrm{BO}_{3}, 5 \mu \mathrm{M} \mathrm{MnSO}_{4}, 1 \mu \mathrm{M} \mathrm{ZnSO}_{4}, 1 \mu \mathrm{M} \mathrm{CuSO}_{4}$,

$467 \quad 0.7 \mu \mathrm{M} \mathrm{NaMoO}_{4}, 1 \mu \mathrm{M} \mathrm{NiSO}_{4}$. Media was changed weekly.

468 - Natural soil. Plants were grown for 9 weeks in a growth chamber under short day condition

469 (8h light $100 \mu \mathrm{E} 19^{\circ} \mathrm{C} / 16 \mathrm{~h}$ dark $17^{\circ} \mathrm{C}$ ) at $18^{\circ} \mathrm{C}$ with a relative humidity of $70 \%$ in a soil

470 collected in the Sutton Bonington campus of the university of Nottingham (GPS coordinate:

$\left.471 \quad 52^{\circ} 49^{\prime} 59.7^{\prime \prime} \mathrm{N} \mathrm{1} 1^{\circ} 14^{\prime} 56.2^{\prime \prime} \mathrm{W}\right)$.

472

\section{Fluorescence microscopy}

474 For lignin staining with basic fuchsin, CASP1-GFP visualisation and calclofluor white M2R staining, 6-day-old roots were fixed in paraformaldehyde and cleared in ClearSee as described (61) and using confocal microscopes (Zeiss LSM500 and Leica SP8). Fluorol yellow 088 staining for visualization of suberin was performed and quantified as described in $(7,58)$ using a fluorescent microscope Leica DM 5000.

\section{Plasmolysis}

481 Plasmolysis was induced by mounting 6-day-old seedlings in 0.8 M mannitol on microscope slides and directly observed using confocal microscopy (Leica SP8). The proportion of the cell wall length in direct contact with the plasma membrane marker SYP122-mCitrine after plasmolysis was measured using Fiji after plasmolysis. This measurement was done on a maximum projection of the top endodermal cells as seen on Supp. Fig 1B. The quantification represents the percentage of cell wall length in direct contact with the plasma membrane marker 
SYP122-mCitrine after plasmolysis. Plasmolysis events were imaged and quantified at 15 cells

488 after the onset of elongation.

489 For the observation of CASP1-GFP and Lignin staining with basic fuchsin, the seedlings were

490 incubated in $0.8 \mathrm{M}$ mannitol for $5 \mathrm{~min}$. and then fixed and cleared as described above.

\section{Thioacidolysis}

493 The plants were grown for 6 days on $1 / 2$ MS plates supplemented with 10 nM 6-

494 Benzylaminopurine (BA) and $0.1 \%$ sucrose. Seeds were sown in three parallel lines per square 495 plates $(12 * 12 \mathrm{~cm})$ at high density. Six plates were combined to obtain one replicate. The first

$4963 \mathrm{~mm}$ of root tips as this zone contains no xylem pole were collected in order to obtain 7 to 15 $497 \mathrm{mg}$ of dry weight. The samples were washed twice with $1 \mathrm{~mL}$ methanol, rotated for 30 minutes 498 on a carousel and centrifugated to eliminate the methanol supernatant. This washing step was 499 repeated once and the final methanol-extracted samples were then dried for 2 days at $40^{\circ} \mathrm{C}$ 500 (oven) before thioacidolysis.

501 The thioacidolyses were carried out in a glass tube with a Teflon-lined screwcap, from about 5 mg sample (weighted at the nearest $0.01 \mathrm{mg}$ ) put together with $0.01 \mathrm{mg} \mathrm{C} 21$ and $0.01 \mathrm{mg} \mathrm{C19}$ internal standard ( $50 \mu \mathrm{L}$ of a $0.2 \mathrm{mg} / \mathrm{ml}$ solution) and with $2 \mathrm{ml}$ freshly prepared thioacidolysis reagent. The tightly closed tubes were then heated at $100^{\circ} \mathrm{C}$ for 4 hours (oil bath), with gentle occasional shaking. After cooling and in each tube, $2 \mathrm{ml}$ of aqueous $\mathrm{NaHCO} 30.2 \mathrm{M}$ solution were added (to destroy the excess of $\mathrm{BF} 3$ ) and then $0.1 \mathrm{ml} \mathrm{HCl} 6 \mathrm{M}$ (to ensure that the $\mathrm{pH}$ is acidic before extraction). The reaction medium was extracted with $2 \mathrm{ml}$ methylene chloride (in the tube) and the lower phase was collected (Pasteur pipette) and dried over $\mathrm{Na}_{2} \mathrm{SO}_{4}$ before evaporation of the solvent (rotoevaporator). The final sample was redissolved in about $2 \mathrm{~mL}$

510 of methylene chloride and $15 \mu \mathrm{L}$ of this solution were trimethylsilylated (TMS) with $50 \mu 1$ 511 BSTFA $+5 \mu 1$ pyridine. The TMS solution was injected $(1 \mu \mathrm{L})$ into a GC-MS Varian 4000 512 instrument fitted with an Agilent combiPAL autosampler, a splitless injector $\left(280^{\circ} \mathrm{C}\right)$, and an 513 ion-trap mass spectrometer (electron impact mode, $70 \mathrm{eV}$ ), with a source at $220{ }^{\circ} \mathrm{C}$, a transfer 514 line at $280{ }^{\circ} \mathrm{C}$, and an $\mathrm{m} / \mathrm{z}$ 50-800 scanning range. The GC column was a Supelco SPB1 515 column $(30 \mathrm{~m} \times 0.25 \mathrm{~mm}$ i.d., film thickness $0.25 \mu \mathrm{m})$ working in the temperature program 516 mode from 45 to $160{ }^{\circ} \mathrm{C}$ at $+30{ }^{\circ} \mathrm{C} / \mathrm{min}$ and then 160 to $260^{\circ} \mathrm{C}$ at $+5{ }^{\circ} \mathrm{C} / \mathrm{min}$, with helium as 517 the carrier gas $(1 \mathrm{~mL} / \mathrm{min})$. The GC-MS determinations of the $\mathrm{H}, \mathrm{G}$, and $\mathrm{S}$ lignin-derived 518 monomers were carried out on ion chromatograms respectively reconstructed at $\mathrm{m} / \mathrm{z} 239,269$, and 299, as compared to the internal standard hydrocarbon evaluated on the ion chromatogram 
reconstructed at $\mathrm{m} / \mathrm{z}(57+71+85) .$. Each genotype was analyzed as biological triplicates and each biological triplicate was subjected to two different silylations and GC-MS analyses.

\section{Raman microscopy}

524 Six-day-old seedling were fixed in PBS buffer containing 4\% formaldehyde and 1\% 525 glutaraldehyde at $4{ }^{\circ} \mathrm{C}$ overnight, then washed twice with PBS $30 \mathrm{~min}$. Samples were progressively dehydrated in ethanol $(30 \%, 50 \%, 70 \%, 100 \%$ ethanol). Samples were aligned and embedded in Leica historesin using the protocol described in Beeckman and Viane. 1999.

528 Sections of $5 \mu \mathrm{m}$ at $4 \mathrm{~mm}$ from the root tip were generated using a Leica microtome.

529 The different samples were embedded in resin and cut at $4 \mathrm{~mm}$ from the root tip using a 530 microtome with a thickness of $15 \mu \mathrm{m}$. Sections were mounted on superfrost glass slides. The samples were then mapped in a grid over the region of interest. The Raman imaging was performed with a Horiba LabRAM HR spectroscope equipped with a piezoelectric scan stage (Horiba Scientific, UK) using a $532 \mathrm{~nm}$ laser, a 100x air objective (Nikon, NA $=0.9$ ) and 600g $\mathrm{mm}^{-1}$ grating. Maps were collected for the regions of interest by setting equidistant points along the sample to ensure maximum coverage. The main regions covered in the analysis were the endodermal cell-cell junction, the endodermal cell corners towards the endodermal-cortical junction and the xylem poles (Figure S1). The maps were acquired with 2 accumulations and $30 \mathrm{~s}$ integration time. The spectra were acquired in the range $300-3100 \mathrm{~cm}^{-1}$. The spectra were processed using MATLAB and eigenvector software. Firstly, the spectra were trimmed (500$1800 \mathrm{~cm}^{-1}$ ), smoothed and then baseline corrected using an automatic least squares algorithm.

541 This was followed by a percentile mean subtraction (10-20\%) to remove signal from the resin.

542 Finally, Gaussian image smoothing was performed to improve signal to noise of the Raman 543 maps. Multivariate Curve Resolution (MCR) analysis was performed on the maps containing

544 the specific ROIs and the corresponding lignin spectra were extracted. These lignin spectra were then used as bounds for the MCR analysis of the large maps where the concentration of these spectra are determined, with a high intensity indicating a high concentration of the specific lignin (Fig. 2C).

\section{RNA-seq}

550 The plants were grown for 6 days on $1 / 2 \mathrm{M} / \mathrm{S}$ plates. Seeds were sown in three parallel lines per square plates $(12 * 12 \mathrm{~cm})$ at high density. The first $5 \mathrm{~mm}$ of root tips were collected. One plate was used as a biological replicate. The samples were snap-frozen at harvest and ground into

553 fine powder in a $2 \mathrm{~mL}$ centrifuge tube. Total RNA was extracted according to Logemann et al., 
554 1987. Samples were homogenized in $400 \mu \mathrm{L}$ of Z6-buffer containing $8 \mathrm{M}$ guanidine-HCl, 20

$555 \mathrm{mM}$ MES, $20 \mathrm{mM}$ EDTA $\mathrm{pH} \quad 7.0$ After the addition of $400 \quad \mu 1$

556 phenol:chloroform:isoamylalcohol, 25:24:1, samples were vortexed and centrifuged $(15,000 \mathrm{~g}$

$55710 \mathrm{~min}$.) for phase separation. The aqueous phase was transferred to a new $1.5 \mathrm{~mL}$ tube and

5580.05 volumes of $1 \mathrm{~N}$ acetic acid and 0.7 volumes $96 \%$ ethanol was added. The RNA was

559 precipitated at $-20^{\circ} \mathrm{C}$ overnight. Following centrifugation $\left(15,000 \mathrm{~g} 10 \mathrm{~min}, 4^{\circ} \mathrm{C}\right)$, the pellet was

560 washed with $200 \mu \mathrm{L} 3 \mathrm{M}$ sodium acetate at $\mathrm{pH} 5.2$ and $70 \%$ ethanol. The RNA was dried and

561 dissolved in $30 \mu \mathrm{L}$ of ultrapure water and store at $-80^{\circ} \mathrm{C}$ until use. DNase treatment (DNase I,

562 Amplification Grade, 18068015, Invitrogen) was carried out on the samples to remove genomic

563 DNA. The RNA Concentration and quality were determined using Qubit (Invitrogen; Q10210)

564 and TapeStation (Agilent; G2991A) protocols. Librairies were generated using the Lexogen

565 Quant Seq 3' mRNA Seq (FWD) Library Prep Kit (Lexogen; 015) which employs polyA

566 selection to enrich for mRNA. Library yield was measured by Qubit (Invitrogen; Q10210) and

567 TapeStation (Agilent; G2991A) systems. protocols to determine concentration and library size,

568 these are then pooled together in equimolar concentrations. The concentration of the pool of

569 libraries were confirmed using the Qubit and qPCR and then loaded onto an Illlumina NextSeq

570 500/550 High Output Kit v2.5 (75 Cycles) (Illumina; 20024906), to generate approximately 5

571 million 75bp single-end reads per sample.

572 Trimmomatic v0.36 was used to identify and discard reads containing the Illumina adaptor

573 sequence. Then, we mapped the resulting high-quality filtered reads against the TAIR10

574 Arabidopsis reference genome using HISAT2 v.2.1.0 with default parameters. Afterwards, we applied the featureCounts function from the Subread package to count reads that mapped to each one of the 27,206 nuclear protein-coding genes.

577 We used the R package DESeq2 v.1.24.0 to identify differentially expressed genes (DEGs)

578 between each genotype (sgn3-3, sgn3-3 myb36-2, sgn3-3 (+CIF2), esb1-1, esb1-1 sgn3-3 and

$579 W T(+C I F 2)$ against WT (Col-0). To do so we fitted the following generalized linear model

580 (GLM).

581

Gene abundance $\sim$ Rep + Genotype

582 A gene was considered statistically differentially expressed if it had a false discovery rate 583 (FDR) adjusted p-value $<0.1$.

584 For visualization purposes we created a standardized gene matrix. To do so, we applied a

585 variance stabilizing transformation to the raw count gene matrix followed up by standardizing

586 the expression of each gene along the samples. We used this standardized gene matrix to 
perform principal coordinate (PC) analysis using the prcomp function in R. We displayed the results of the PC analysis using ggplot2.

589 Additionally, we subset the 3266 statistically significant DEGs from the standardized gene 590 matrix. Then, for each DEG we calculated its mean expression across each genotype followed

591 up by hierarchical clustering (R function hclust method ward.D2) using the euclidean distance

592 for the genotypes and the correlation dissimilarity for the genes. To define the 7 clusters of

593 cohesively expressed genes, we cut the gene dendrogram from the hierarchical clustering using

594 the R function cutree. We visualized the expression of the 3266 DEGs and the result of the 595 clustering approach using ggplot2. We used the compareCluster function from the 596 clusterProfiler R package to perform gene ontology (GO) analysis for the 7 clusters of 597 cohesively expressed DEGs.

598 We constructed individual heatmaps for the phenylpropanoid pathway and the aquaporin genes

599 by subsetting the corresponding curated gene ids from the standardized gene matrix and 600 procedure described above.

601 Raw sequence data and read counts are available at the NCBI Gene Expression Omnibus accession number (GEO: GSE158809). Additionally, the scripts created to analyse the RNASeq data can be found at https://github.com/isaisg/schengenlignin

\section{Extraction and profiling of metabolites}

606 The plants (WT, esb1-1, sgn3-3 and esb1-1 sgn3-3) were grown for 6 days on 1/2 M/S plates 607 supplemented with $0.1 \%$ sucrose. Seeds were sown in three parallel lines per square plates $608(12 * 12 \mathrm{~cm})$ at high density. The first $5 \mathrm{~mm}$ of root tips were collected in order to obtain 10 to $60920 \mathrm{mg}$ of dry weight per replicate. Eight plates were combined to obtain one replicate. Eight 610 replicates per genotypes were harvested. The samples were snap-frozen at harvest and ground 611 into fine powder in a $2 \mathrm{~mL}$ centrifuge tube then homogenized in liquid nitrogen and extracted 612 with $1 \mathrm{ml}$ methanol. The methanol extract was then evaporated, and the pellet dissolved in 200 $613 \mu \mathrm{l}$ water / cyclohexane $(1 / 1, \mathrm{v} / \mathrm{v}) \cdot 10 \mu \mathrm{l}$ of the aqueous phase was analyzed via reverse phase 614 UltraHigh Performance Liquid Chromatography (UHPLC; Acquity UPLC Class 1 systems 615 consisting of a Sample Manager-FTN, a Binary Solvent Manager and a Column Manager, 616 Waters Corporation, Milford, MA) coupled to negative ion ElectroSpray Ionization617 Quadrupole-Time-of-Flight Mass Spectrometry (ESI-Q-ToF-MS; Vion IMS QTof, Waters 618 Corporation) using an Acquity UPLC BEH C18 column (1.7 $\mu \mathrm{m}, 2.1$ x $150 \mathrm{~mm}$; Waters 619 Corporation). Using a flow rate of $350 \mu \mathrm{l} / \mathrm{min}$ and a column temperature of $40{ }^{\circ} \mathrm{C}$, a linear 620 gradient was run from $99 \%$ aqueous formic acid $(0.1 \%$, buffer $\mathrm{A})$ to $50 \%$ acetonitrile $(0.1 \%$ 
621 formic acid, buffer B) in $30 \mathrm{~min}$, followed by a further increase to $70 \%$ and then to $100 \%$ buffer

622 B in 5 and $2 \mathrm{~min}$, respectively. Full MS spectra $(\mathrm{m} / \mathrm{z} 50-\mathrm{m} / \mathrm{z}$ 1,500) were recorded at a scan

623 rate of $10 \mathrm{~Hz}$. The following ESI parameters were used: capillary voltage $2.5 \mathrm{kV}$, desolvation

624 temperature $550{ }^{\circ} \mathrm{C}$, source temperature $120^{\circ} \mathrm{C}$, desolvation gas $800 \mathrm{~L} / \mathrm{h}$ and cone gas $50 \mathrm{~L} / \mathrm{h}$.

625 Lock correction was applied. In addition to full MS analysis, a pooled sample was subjected to

626 data dependent MS/MS analysis (DDA) using the same separation conditions as above. DDA

627 was performed between $\mathrm{m} / \mathrm{z} 50$ and $\mathrm{m} / \mathrm{z} 1,200$ at a scan rate of $5 \mathrm{~Hz}$ and $\mathrm{MS}->\mathrm{MS} / \mathrm{MS}$

628 transition collision energy of $6 \mathrm{eV}$. The collision energy was ramped from 15 to $35 \mathrm{eV}$ and

629 from 35 to $70 \mathrm{eV}$ for the low and high mass precursor ions, respectively.

630 Integration and alignment of the $\mathrm{m} / \mathrm{z}$ features were performed via Progenesis QI software

631 version 2.1 (Waters Corporation). The raw data were imported in this software using a filter

632 strength of 1. A reference chromatogram was manually chosen for the alignment procedure

633 and additional vectors were added in chromatogram regions that were not well aligned. Peak

634 picking was based on all runs with a sensitivity set on 'automatic' (value $=5$ ). The

635 normalization was set on 'external standards' and was based on the dry weight of the samples

636 (62). In total, $13,091 \mathrm{~m} / \mathrm{z}$ features were integrated and aligned across all chromatograms.

637 Structural annotation was performed using a retention time window of $1 \mathrm{~min}$, and using both

638 precursor ion and MS/MS identity searches. The precursor ion search (10 ppm tolerance) was

639 based on a compound database constructed via instant JChem (ChemAxon, Budapest,

640 Hungary), whereas MS/MS identities were obtained by matching against an in-house mass

641 spectral database (200 ppm fragment tolerance).

642 Using R vs 3.4.2., $\mathrm{m} / \mathrm{z}$ features representing the same compound were grouped following the 643 algorithm in (63). Of the $13,091 \mathrm{~m} / \mathrm{z}$ features, 12,326 were combined into $2,482 \mathrm{~m} / \mathrm{z}$ feature 644 groups, whereas 765 remained as $\mathrm{m} / \mathrm{z}$ feature singlets (i.e. low abundant features). All 645 statistical analyses were performed in R vs. 3.4 .2 (64). Including all m/z features and upon 646 applying a prior inverted hyperbolic sine transformation (65), the data were analyzed via both 647 Principal Component Analysis (PCA) and one-way analysis of variance (ANOVA; $\operatorname{lm}($ ) 648 function) followed by Tukey Honestly Significant Difference (Tukey HSD; TukeyHSD() 649 function) post hoc tests. For PCA, the R packages FactoMineR (66) and factoextra 650 (https:/CRAN.R-project.org/package=factoextra) were employed: 651 PCA(scale.unit=T,graph=F), fviz_pca_ind() and fviz_pca_biplot(). Following ANOVA 652 analysis, experiment-wide significant models were revealed via a false discovery rate (FDR) 653 correction using the p.adjust(method="fdr") function. Using a FDR-based Q value $<0.05$, 6544,244 of the $13,091 \mathrm{~m} / \mathrm{z}$ features were significantly changed in abundance corresponding to 
$655123 \mathrm{~m} / \mathrm{z}$ feature singlets and 1,158 of the 2,482 compounds. Using a minimum abundance 656 threshold of 500 in at least one of the lines, further analysis was performed on 411 of the 1,158

657 compounds and 11 of the $123 \mathrm{~m} / \mathrm{z}$ feature singlets ( 411 compounds and 11 singlets representing 658 together $889 \mathrm{~m} / \mathrm{z}$ features).

659

\section{Root Hydraulic conductivity}

661 The procedure was exactly identical to the one described in (24). Root hydrostatic conductance $662(\mathrm{Kr})$ was determined in freshly detopped roots using a set of pressure chambers filled with 663 hydroponic culture medium. Excised roots were sealed using dental paste (Coltène/Whaledent 664 s.a.r.l., France) and were subjected to $350 \mathrm{kPa}$ for $10 \mathrm{~min}$ to achieve flow stabilization, followed 665 by successive measurements of the flow from the hypocotyl at pressures 320,160 , and 240 $666 \mathrm{kPa}$. Root hydrostatic conductance $(\mathrm{Kr})$ was calculated by the slope of the flow $(\mathrm{Jv})$ to pressure 667 relationship. The hydrostatic water conductivity $\left(L \mathrm{p}_{\mathrm{r}-\mathrm{h}}, \mathrm{ml} \mathrm{H} 2 \mathrm{O} \mathrm{g}^{-1} \mathrm{~h}^{-1} \mathrm{MPa}^{-1}\right)$ was calculated 668 by dividing $\mathrm{Kr}$ by the root dry weight.

669

\section{Determination of the leaf surface area, mortality and siliques number}

671 For the determination of the leaf surface and mortality, the seeds were stratified for two days 672 at $4^{\circ} \mathrm{C}$ and the plants were grown in Levington M3 compost in a growth chamber under long 673 day condition ( $16 \mathrm{~h}$ light $100 \mu \mathrm{E} 21^{\circ} \mathrm{C} / 8 \mathrm{~h}$ dark $19^{\circ} \mathrm{C}$ ). The plants were grown for 7 days with 674 high relative humidity $(80 \%)$ and then half of the plants were transferred at a lower humidity 675 (65\%). Leaf surface was determined at 6, 9, 12 and 15 days after germination using the 676 threshold command of the FiJi software (Schindelin et al., 2012). The plants displaying no 677 growth after 9 days and showing necrosis in all the leave surface were considered as dead 678 plants.

679 For the determination of the siliques number, the plants were cultivated in a high humidity 680 environment for 10 days after germination and then transferred to a greenhouse. After siliques 681 ripening, only the seeds containing siliques were counted.

682

\section{Ionomic analysis with ICP-MS}

684 Ionomics analysis of plants grown in soil (or on plate, hydroponically) was performed as 685 described (67). Briefly, samples (leaf, shoot, root or seed) were harvested into Pyrex test tubes $686(16 \times 100 \mathrm{~mm})$ and dried at $88 \mathrm{oC}$ for $20 \mathrm{~h}$. After weighing the appropriate number of samples 687 (these masses were used to calculate the rest of the sample masses; alternatively, all samples 688 were weighed individually - usually for small set of samples), the trace metal grade nitric acid 
689 Primar Plus (Fisher Chemicals) spiked with indium internal standard was added to the tubes (1

$690 \mathrm{~mL}$ per tube). The samples were then digested in dry block heater (DigiPREP MS, SCP

691 Science; QMX Laboratories, Essex, UK) at $115^{\circ} \mathrm{C}$ for 4 hours. The digested samples were

692 diluted to $10 \mathrm{~mL}$ with 18.2 M $\mathrm{cm}$ Milli-Q Direct water (Merck Millipore). Elemental analysis

693 was performed with an inductively coupled plasma-mass spectrometry (ICP-MS), PerkinElmer

694 NexION 2000 equipped with Elemental Scientific Inc. autosampler, in the collision mode (He).

695 Twenty elements (Li, B, Na, Mg, P, S, K, Ca, Mn, Fe, Co, Ni, Cu, Zn, As, Se, Rb, Sr, Mo and

696 Cd) were monitored. Liquid reference material composed of pooled samples was prepared

697 before the beginning of sample run and was used throughout the whole samples run. It was run

698 after every ninth sample to correct for variation within ICP-MS analysis run (67). The

699 calibration standards (with indium internal standard and blanks) were prepared from single

700 element standards (Inorganic Ventures; Essex Scientific Laboratory Supplies Ltd, Essex, UK)

701 solutions. Sample concentrations were calculated using external calibration method within the

702 instrument software. Further data processing was performed using Microsoft Excel 703 spreadsheet.

\section{Acknowledgements}

706 We thank Deep Seq (Next Generation Sequencing Facility of the University of Nottingham,

707 UK), the nmRC (Nanoscale and Microscale Research Centre of the University of Nottingham, 708 UK), the Microscopy and Histology Facility of the University of Aberdeen (UK), the VIB 709 Metabolomics Core (VIB-UGent, Belgium). This work was supported by grants from the UK 710 Biotechnology and Biological Sciences Research Council Grant (grant no. BB/N023927/1 to

711 D.E.S.), the Coordinating Action in Plant Sciences Promoting sustainable collaboration in plant 712 sciences (grant no. ERACAPS13.089_RootBarriers to DES), the Engineering and Physical 713 Sciences Research Council (grant no. EP/R025282/1) and the Future Food Beacon of 714 Excellence at the University of Nottingham (Nottingham Research Fellowship to GC, and 715 Postdoctoral Research Fellowship to GR) 
719 Figure 1. Disruption of $M Y B 36$ and $S G N 3$ abolish endodermal lignification and root apoplastic barrier.

(A) Maximum projection of lignin staining at the $6^{\text {th }}$ and $10^{\text {th }}$ endodermal cell after the onset of elongation. Spiral structures in the centre of the root are xylem. Scale bar $=10 \mu \mathrm{m}$. Median (B) and surface (C) view of an endodermal cell at 10 cells after the onset of elongation. Scale bar $=5 \mu \mathrm{m}$. The roots were cleared and stained with basic fuchsin (yellow) for lignin and with Calcofluor white (blue) for cellulose. (D) Boxplot showing the percentage of the root length permeable to propidium iodide. $\mathrm{n}=18$ from two independent experiments. Different letters represent significant differences between genotypes using a Mann-Whitney test $(p<0.01)$. (E) Quantification of suberin staining along the root. The results are expressed in percentage of root length divided in three zones: unsuberised (white), discontinuously suberised (yellow), continuously suberised (orange). $\mathrm{n}=6$, error bars: SD. Individual letters show significant differences using a Mann-Whitney test between the same zones $(p<0.01)$.

\section{Figure 2. Activation of the Schengen-pathway triggers the deposition of a distinct "stress" lignin in the endodermis.}

(A) Raman spectra of lignin of the different regions of interest presented in Sup. Fig. 1 and determined using a Multivariate Curve Resolution (MCR) analysis. The MCR analysis was performed on small Raman maps from independent plants containing CS lignin of WT $(n=8)$, cell-corner lignin of WT treated with CIF2 $(+\mathrm{CIF} 2 ; \mathrm{n}=5)$ and for xylem lignin of WT $(n=2)$ and xylem lignin of WT treated with CIF2 $(n=2)$. (B) Close view of Raman spectra presented in (A) in the lignin aromatic region between $1550 \mathrm{~cm}^{-1}$ and $1700 \mathrm{~cm}^{-1}$. (C) Large Raman maps of roots of WT and WT treated with CIF2 (+CIF2). The intensity of the different lignin spectra presented in (A) was mapped onto large Raman maps containing xylem and endodermal lignin. (D) Lignin staining with basic fuchsin at a distance of $3 \mathrm{~mm}$ from the root tip in WT, ahp6-1, ahp6-1esb1-1, ahp6-1esb1-1sgn3-3, ahp6-1myb36-2 and ahp6-1 treated with CIF2. The plants were grown for 6 days in presence of $10 \mathrm{nM}$ 6-Benzylaminopurine (BA). Upper panel shows a maximum projection of the root (Scale bar $=10 \mu \mathrm{m}$ ). Spiral structures in the centre only observed in the WT root are protoxylem. Lower panel shows surface view of endodermal cells (Scale bar $=5 \mu \mathrm{m}$ ). White arrows indicate ectopic lignification. (E) Relative abundance of the lignin monomers released by thioacidolysis ( $p$-hydroxyphenyl $(\mathrm{H})$, guaiacyl $(\mathrm{G})$, and syringyl (S) units) in root tips of ahp6-1 ( $\mathrm{n}=9)$, ahp6-1 treated with CIF2 (+CIF2; $\mathrm{n}=3)$, ahp6-1esb1-1 $\mathrm{n}=6$, ahp6-1 myb36-2 ( $\mathrm{n}=6)$ and ahp6-1 esb1-1 sgn3-3 $(\mathrm{n}=6)$. Asterisks represent significant differences from the ahp6-1 control for each individual monomer using a Mann-Whitney U test $(p$-value $<0.01)$.

\section{Figure 3. Modulation of the phenylpropanoid pathway by the Schengen-pathway.}

(A) Heatmap of the 3266 differentially expressed genes identified in the RNA-seq in root tips of wild-type (WT), sgn3-3, esb1-1, myb36-2, esb1-1 sgn3-3, sgn3-3 myb36-2 plants. Treatment with $100 \mathrm{nM}$ CIF2 was applied as indicated (+CIF2) for WT and sgn3-3 plants. Clusters (C) are designated with numbers $(n=6)$. Genes belonging to each cluster are listed in Sup. Table 1. (B) Phenylpropanoid pathway leading to the lignin monomers and scopoletin biosynthesis (adapted from and (68)). Solid arrows represent enzymatic steps. Gene expression from the genes selected in Sup. Fig. 3C were mapped on the pathway according to their KEGG enzyme nomenclature. Only the genes with a demonstrated function in lignin biosynthesis as listed in Sup. Fig. 3C were mapped. PAL, PHENYLALANINE AMMONIA-LYASE; C4H, CINNAMATE 4-HYDROXYLASE; 4CL, 4-COUMARATE:CoA LIGASE; HCT, $p$ HYDROXYCINNAMOYL-COA:QUINATE/SHIKIMATE $p-$ HYDROXYCINNAMOYLTRANSFERASE; C'3H, $p$-COUMARATE 3'-HYDROXYLASE; 
C3H, COUMARATE 3-HYDROXYLASE; CSE, CAFFEOYL SHIKIMATE ESTERASE; CCOAOMT, CAFFEOYL-COA O-METHYLTRANSFERASE; CCR, CINNAMOYL-CoA REDUCTASE; F5H, FERULATE 5-HYDROXYLASE; COMT, CAFFEIC ACID OMETHYLTRANSFERASE; CAD, CINNAMYL ALCOHOL DEHYDROGENASE; HCALDH, HYDROXYCINNAMALDEHYDE DEHYDROGENASE; COSY, COUMARIN SYNTHASE; F6'H1 FERULOYL COA ORTHO-HYDROXYLASE 1.

\section{Figure 4. PM attachment to the $\mathrm{CW}$ is MYB36-dependent but does not rely on lignin deposition.}

(A) Median and surface view of the endodermal plasma membrane using the marker line pELTP::SYP122mCitrine before plasmolysis $\left(+\mathrm{H}_{2} \mathrm{O}\right)$ and after plasmolysis (+Mannitol) at 15 cells after the onset of elongation. WT plants were treated or not from germination with $10 \mu \mathrm{M}$ piperonylic acid (+PA). White asterisks show the exclusion domain at the CSD. The dashed line represents the contours of the cells before plasmolysis. Arrows show the plasma membrane attachment to the cell wall. Blue asterisks show the plasmolysis generated space where no attachment is observed. Scale bar $=5 \mu \mathrm{m}$. "inner" designates the stele-facing endodermal surface, "outer", the cortex-facing surface. (B) Maximum projection of CASP1-GFP and lignin staining with basic fuchsin in cleared roots from plants grown with or without $10 \mu \mathrm{M}$ piperonylic acid and subjected to plasmolysis with Mannitol. Scale bar $=10 \mu \mathrm{m}$.

Figure 5. Absence of endodermal apoplastic barrier triggers major ionomic changes.

(A) Overview of ions accumulation in shoot of sgn3-3, myb36-2 and sgn3-3 myb36-2 mutants compared to WT using different growth conditions in agar plates (long day, $n=10$ ), in hydroponics (short day, $n=6$ ) and natural soil (short day, $n \geq 13$ ). Elements concentration were determined by ICP-MS and are available in the Sup. Table 3. Colour code indicates significant changes in accumulation compared with the WT using a $t$ test $(\mathrm{p}<0.01)$. (B) Principal component analysis (PCA) based on the concentration of 20 elements in shoots of plants grown in agar plates. Ellipses show confidence level at a rate of $90 \% . n=10(\mathbf{C})$ Plots presenting the correlation between the z-scores of elements content in shoots of plants grown in agar plates of WT, myb36-2, sgn3-3 and sgn3-3 myb36-2 against the portion of root length permeable to propidium iodide as determined in Fig. 1D. The black lines show the average and the grey area show the $95 \%$ confidence interval $(n=10)$.

800

Figure 6. Activation of the Schengen-pathway represses water transport and maintains plant growth, survival and fitness under fluctuating environment

803

(A) Hydrostatic root hydraulic conductivity $\left(L \mathrm{p}_{\mathrm{r}-\mathrm{h}}\right)$ in WT, sgn3-3, myb36-2, sgn3-3 myb36-2 grown hydroponically for 19-21 days under environmental controlled conditions. Hydraulic conductivity was measured using pressure chambers $\left(L \mathrm{p}_{\mathrm{r}-\mathrm{h}}\right)$ (means $\left.\pm \mathrm{SE}, \mathrm{n} \geq 3\right)$. (B) Heatmap of aquaporins expression across the different genotypes and treatments used in the RNAseq experiment. (C) Representative pictures of WT, sgn3-3, myb36-2, sgn3-3 myb36-2, WT 808 pELTP ::CDEF and sgn3-3 myb36-2 - pELTP ::CDEF plants germinated in soil with a high 809 humidity (80\%) for 7 days and then transferred in an environment with a lower $(60 \% \mathrm{RH})$ or 810 with constant humidity $(80 \% \mathrm{RH})$. Pictures were taken $0,2,5$ and 8 days after the transfer. 811 Scale bar $=1 \mathrm{~cm}$. (D) Boxplots showing the proportion of dead plants after transfer in an environment with constant humidity $(80 \% \mathrm{RH}$, blue) or with a lower $(60 \% \mathrm{RH}$, red). The plants displaying no growth after 9 days and showing necrosis in all the leave surface were considered as dead plants. Each point represents the proportion of dead plants in a cultivated pot compared to the total number of plants for one genotype in the same pot. Pots were containing at least 8 plants of each genotypes, $n=10$ pots. Different letters represent significant differences between genotypes using a Mann-Whitney test $(\mathrm{p}<0.01)$. (E) Boxplots showing the number of siliques 
818 produced per plants. Plants were cultivated in a high humidity environment for 10 days after 819 germination and then transferred to a greenhouse. Each point represents the total number of seeds containing siliques per plant $(\mathrm{n} \geq 12)$. Different letters represent significant differences between genotypes using a Mann-Whitney test $(\mathrm{p}<0.01)$.

822

823

824

825

\section{SUPPLEMENTARY FIGURES LEGEND}

\section{Supplemental Figure 1. Activation of the Schengen-pathway triggers the deposition of a distinct "stress" lignin in the endodermis.}

827 Examples of small Raman maps for endodermal cells of WT $(\varnothing)$ and WT(+CIF2) and for xylem 828 of WT(Ø) and WT(+CIF2) used for determining the lignin spectra using Multivariate Curve 829 Resolution (MCR) presented in Fig. 2 C-D. The colour code represents the intensity of the lignin factor presented in Fig. 2 C-D.

\section{Supplemental Figure 2. Gene expression profiling in response to the activation of the Schengen-pathway.}

(A) Principal component analysis (PCA) of the differentially expressed genes identified in root tips of wild-type (WT), sgn3-3, esb1-1, myb36-2, esb1-1 sgn3-3, sgn3-3 myb36-2 plants. Treatment with $100 \mathrm{nM}$ CIF2 was applied as indicated (+CIF2) for WT and sgn3-3 plants (n = 6). (B) Gene ontology enrichment in the different gene clusters from Fig. 3A. The colour of each point represents the $\mathrm{p}$-value adjusted using the Benjamin-Hochberg procedure, and the size of each point denotes the percentage of total differential expressed genes in the given gene ontology term (Gene Ratio). (C) Heatmap of gene expression of genes related to the phenylpropanoid pathway (black) (69) and their transcriptional regulators (grey) (43, 70). Genes names are given according to (71) for genes related to the phenylpropanoid pathway. Asterisks indicate demonstrated function in lignin biosynthesis with an activity demonstrated in vitro or in vivo according to (72) for PAL1-4, to for $(73) C 4 H,(74,75)$ for $4 C L 1-4,(76,77)$ for $C C R 1$ and $2,(78,79)$ for $C A D 1,2$ and $6,(80)$ for $C 3{ }^{\prime} H,(81)$ for $C 3 H,(82)$ for $C O M T$ and CCoAOMT1, (83) for HCT, (84) for CSE, (85) for ALDH1A, (45) for F6'H1, (46) for COSY and (86) for $\mathrm{F} 5 \mathrm{Hl}$.

Supplemental Figure 3. Metabolite profiling in response to the activation of the Schengenpathway.

851 Heatmaps of metabolite profiling determined using Ultra High Performance Liquid Chromatography (UHPLC) in $5 \mathrm{~mm}$ roots tips of wild-type (WT), sgn3-3, esb1-1 sgn3-3 and esb1-1. The heatmaps show all the compounds (2497, left) and characterised compounds (52, right) that are differentially accumulated ( $q$-value $<0.01$, left; $q$-value $<0.1$, right $\mathrm{n}=8$ ). Underlined names are for compounds that are only differentially accumulated (q-value $<0.1$ ) in esb1-1 and not changed in sgn3-3 and esb1-1 sgn3-3 in comparison with WT. Data for the known compounds are presented in Sup. Table 3.

\section{Supplemental Figure 4. Plasma membrane attachment to the cell wall.}

(A) Maximum projection of the top endodermal cells as shown in the schematic view. The observations were done in lines expressing the plasma membrane marker line pELTP::SYP122mCitrine before plasmolysis $\left(+\mathrm{H}_{2} \mathrm{O}\right)$ and after plasmolysis ( + Mannitol) at 15 cells after the onset of elongation. The dashed line represents the contours of the cells. Asterisks show the plasmolysis generated space where no attachment is observed. Scale bar $=5 \mu \mathrm{m}$. Representative pictures are shown. 
867 Supplemental Figure 5. Absence of endodermal apoplastic barrier triggers major 868 ionomic changes in different growth conditions.

869 Principal component analysis (PCA) based on the concentration of 20 elements in shoots of 870 WT, sgn3-3, myb36.3 and sgn3-3 myb36-2 plants grown in (A) hydroponics (short day, $\mathrm{n}=6$ ) and (B) natural soil (short day, $\mathrm{n} \geq 13$ ). Ellipses show confidence level at a rate of $90 \%$. (C) Pictures of 2-week-old wild-type (WT), sgn3-3, myb36-2 and sgn3-3 myb36-2 plants grown in agar plates. (D-E) Boxplots showing the primary root length (D) and lateral roots density (E) of 2-week-old WT, sgn3-3, myb36-2 and sgn3-3 myb36-2 plants grown in agar plates. Letters show significantly different groups according to a Tukey's test as post hoc analyses $(\mathrm{n} \geq 41$, $\mathrm{P}<0.01$ ). (F) Pictures of 5-week-old WT, sgn3-3, myb36-2 and sgn3-3 myb36-2 plants grown in hydroponics. Scale bar $=1 \mathrm{~cm}$. (G) Pictures of 9-week-old WT, sgn3-3, myb36-2 and sgn33 myb36-2 plants grown in natural soil. Scale bar $=3 \mathrm{~cm}$.

\section{Supplemental Figure 6. Activation of the Schengen-pathway maintains plant growth under fluctuating environment.}

882

883

(A) Quantification of suberin staining along the root of 6 days-old plants. The results are expressed in percentage of root length divided in three zones: unsuberised (white), discontinuously suberised (yellow), continuously suberised (orange). $\mathrm{n}=7$, error bars: SD. Individual letters show significant differences using a Mann-Whitney test between the same zones $(\mathrm{p}<0.01)$. (B) Graphs showing leaf surface area of WT, sgn3-3, myb36-2, sgn3-3 myb362, WT-pELTP ::CDEF and sgn3-3 myb36-2-pELTP::CDEF plants germinated in soil with a high humidity $(80 \%)$ for 7 days and then transferred in an environment with constant $(80 \%$ $\mathrm{RH}$, blue) or with a lower humidity $(60 \% \mathrm{RH}$, red). Data were collected $0,2,5$ and 8 days after the transfer. Each point is the average leave surface per plant from a singles pot ( $\mathrm{n} \geq 6$ pots). Each pot contained at least 6 plants for each genotype. The line shows the average value for each measured time points. Black asterisk indicates a significant difference between high and low humidity for a same genotype at one time point. Blue and red asterisk indicate a significant difference in comparison with WT at the same time point respectively for the high and low humidity environment. The significant differences were calculated using a Tukey's test as post hoc analyses $(\mathrm{p}<0.01)$.

Supplemental Table 1. List of the differentially expressed genes in the RNA-seq experiment.

List of the differentially expressed genes identified in the RNA-seq in root tips of wild-type (WT), sgn3-3, esb1-1, myb36-2, esb1-1 sgn3-3, sgn3-3 myb36-2 plants. Treatment with 100 nM CIF2 was applied as indicated (+CIF2) for WT and sgn3-3 plants.

\section{Supplemental Table 2. Metabolite profiling in response to the activation of the Schengen- pathway.}

\section{Supplemental Table 3. Absence of endodermal apoplastic barrier triggers major ionomic changes.}

Elemental content in shoot of sgn3-3, myb36-2 and sgn3-3 myb36-2 mutants compared to WT using different growth conditions in agar plates (long day, $\mathrm{n}=10$ ), in hydroponics (short day, $\mathrm{n}=6$ ) and natural soil (short day, $\mathrm{n} \geq 13$ ). Elements concentration were determined by ICP-MS. Data are presented as mean \pm standard deviation (SD). $t$ tests were performed to determine the significant differences to WT and the corresponding p-values are presented. 
bioRxiv preprint doi: https://doi.org/10.1101/2020.10.07.329664; this version posted October 8, 2020. The copyright holder for this preprint (which was not certified by peer review) is the author/funder, who has granted bioRxiv a license to display the preprint in perpetuity. It is made available under aCC-BY-NC-ND 4.0 International license.

\section{References}

917 1. Boerjan W, Ralph J, Baucher M (2003) Lignin biosynthesis. Annu Rev Plant Biol 54:519-546.

918 2. Lee MH, et al. (2019) Lignin-based barrier restricts pathogens to the infection site and confers resistance in plants.

919 The EMBO Journal 38(23):e1745-17.

9203 3. Vanholme R, De Meester B, Ralph J, Boerjan W (2019) Lignin biosynthesis and its integration into metabolism.

$921 \quad$ Current Opinion in Biotechnology 56:230-239.

922 4. Tobimatsu Y, Schuetz M (2018) Lignin polymerization: how do plants manage the chemistry so well? Current

923 Opinion in Biotechnology 56:75-81.

924 5. Schuetz M, et al. (2014) Laccases direct lignification in the discrete secondary cell wall domains of protoxylem.

925 PLANT PHYSIOLOGY 166(2):798-807.

926 6. Barros J, Serk H, Granlund I, Pesquet E (2015) The cell biology of lignification in higher plants. Annals of

927 Botany:mcv046.

928 7. Naseer S, et al. (2012) Casparian strip diffusion barrier in Arabidopsis is made of a lignin polymer without suberin.

929 Proc Natl Acad Sci USA 109(25):10101-10106.

$930 \quad 8 . \quad$ Geldner N (2013) The endodermis. Annu Rev Plant Biol 64(1):531-558.

9319.9 Pfister A, et al. (2014) A receptor-like kinase mutant with absent endodermal diffusion barrier displays selective

10. Baxter I, et al. (2012) Biodiversity of Mineral Nutrient and Trace Element Accumulation in Arabidopsis thaliana. PLoS ONE 7(4):e35121.

11. Barbosa ICR, Rojas-Murcia N, Geldner N (2018) The Casparian strip —one ring to bring cell biology to lignification? Current Opinion in Biotechnology 56:121-129.

12. Roppolo D, et al. (2011) A novel protein family mediates Casparian strip formation in the endodermis. Nature 473(7347):380-383.

13. Rojas-Murcia N, et al. (2020) High-order mutants reveal an essential requirement for peroxidases but not laccases in Casparian strip lignification. bioRxiv:2020.06.17.154617.

14. Lee Y, Rubio MC, Alassimone J, Geldner N (2013) A Mechanism for Localized Lignin Deposition in the Endodermis. Cell 153(2):402-412.

15. Hosmani PS, et al. (2013) Dirigent domain-containing protein is part of the machinery required for formation of the lignin-based Casparian strip in the root. Proc Natl Acad Sci USA 110(35):14498-14503.

16. Liberman LM, Sparks EE, Moreno-Risueno MA, Petricka JJ, Benfey PN (2015) MYB36 regulates the transition from proliferation to differentiation in the Arabidopsis root. Proc Natl Acad Sci USA:201515576.

17. Kamiya T, et al. (2015) The MYB36 transcription factor orchestrates Casparian strip formation. Proc Natl Acad Sci USA:201507691.

18. Fujita S, et al. (2020) SCHENGEN receptor module drives localized ROS production and lignification in plant roots. The EMBO Journal:e103894.

19. Nakayama T, et al. (2017) A peptide hormone required for Casparian strip diffusion barrier formation in Arabidopsis roots. Science 355(6322):284-286.

20. Doblas VG, et al. (2017) Root diffusion barrier control by a vasculature-derived peptide binding to the SGN3 receptor. Science 355(6322):280-284.

21. Alassimone J, et al. (2016) Polarly localized kinase SGN1 is required for Casparian strip integrity and positioning. Nature Plants:1-10

22. Li B, et al. (2017) Role of LOTR1 in Nutrient Transport through Organization of Spatial Distribution of Root Endodermal Barriers. Curr Biol:1-9.

23. Alassimone J, Naseer S, Geldner N (2010) A developmental framework for endodermal differentiation and polarity. Proc Natl Acad Sci USA 107(11):5214-5219.

24. Wang P, et al. (2019) Surveillance of cell wall diffusion barrier integrity modulates water and solute transport in plants. Scientific Reports 9(1):4227.

25. Agarwal UP, McSweeny JD, Ralph SA (2011) FT-Raman Investigation of Milled-Wood Lignins: Softwood, Hardwood, and Chemically Modified Black Spruce Lignins. Journal of Wood Chemistry and Technology 31(4):324-344.

26. Mahonen AP (2006) Cytokinin Signaling and Its Inhibitor AHP6 Regulate Cell Fate During Vascular Development. Science 311(5757):94-98.

27. Lange BM, Lapierre C, Sandermann H Jr (1995) Elicitor-Induced Spruce Stress Lignin (Structural Similarity to Early Developmental Lignins). Plant Physiol 108(3):1277.

28. Fukushima K, Terashima N (1991) Heterogeneity in formation of lignin. Wood Science and Technology 25(5):371381.

29. Westermark U (1985) The occurrence of p-hydroxyphenylpropane units in the middle-lamella lignin of spruce (Picea abies). Wood Science and Technology 19(3):223-232.

30. Lapierre C (1995) Application of New Methods for the Investigation of Lignin Structure. Forage Cell Wall Structure and Digestibility (John Wiley \& Sons, Ltd), pp 133-166.

31. Ride JP (1975) Lignification in wounded wheat leaves in response to fungi and its possible rôle in resistance. Physiological Plant Pathology 5(2):125-134.

32. Hammerschmidt R, Bonnen AM, Bergstrom GC, Baker KK (1985) Association of epidermal lignification with nonhost resistance of cucurbits to fungi. Can J Bot 63(12):2393-2398.

33. Doster MA, Bostock RM (1988) Quantification of lignin formation in almond bark in response to wounding and infection by Phytophthora species. Phytopathology 78(4):473-477. 
bioRxiv preprint doi: https://doi.org/10.1101/2020.10.07.329664; this version posted October 8,2020 . The copyright holder for this preprint (which was not certified by peer review) is the author/funder, who has granted bioRxiv a license to display the preprint in perpetuity. It is made available under aCC-BY-NC-ND 4.0 International license.

982 34. Lange BM, Lapierre C, (null) HSJP (1995) Elicitor-induced spruce stress lignin (structural similarity to early 
bioRxiv preprint doi: https://doi.org/10.1101/2020.10.07.329664; this version posted October 8,2020 . The copyright holder for this preprint (which was not certified by peer review) is the author/funder, who has granted bioRxiv a license to display the preprint in perpetuity. It is made available under aCC-BY-NC-ND 4.0 International license.

67. Danku JMC, Lahner B, Yakubova E, Salt DE (2013) Large-scale plant ionomics. Methods Mol Biol 953(Chapter 17):255-276.

68. Vanholme B, Houari El I, Boerjan W (2018) Bioactivity: phenylpropanoids' best kept secret. Current Opinion in Biotechnology 56:156-162.

69. Mueller LA, Zhang P, Rhee SY (2003) AraCyc: a biochemical pathway database for Arabidopsis. PLANT PHYSIOLOGY 132(2):453-460.

70. Ohtani M, Demura T (2018) The quest for transcriptional hubs of lignin biosynthesis: beyond the NAC-MYB-gene regulatory network model. Current Opinion in Biotechnology 56:82-87.

71. Raes J, Rohde A, Christensen JH, Van de Peer Y, Boerjan W (2003) Genome-wide characterization of the lignification toolbox in Arabidopsis. PLANT PHYSIOLOGY 133(3):1051-1071.

72. Huang J, et al. (2010) Functional Analysis of the Arabidopsis \&lt;em\&gt;PAL\&lt;/em\&gt; Gene Family in Plant Growth, Development, and Response to Environmental Stress. Plant Physiol 153(4):1526.

73. Schilmiller AL, et al. (2009) Mutations in the cinnamate 4-hydroxylase gene impact metabolism, growth and development in Arabidopsis. The Plant Journal 60(5):771-782.

74. Costa MA, et al. (2005) Characterization in vitro and in vivo of the putative multigene 4-coumarate:CoA ligase network in Arabidopsis: syringyl lignin and sinapate/sinapyl alcohol derivative formation. The International Journal of Plant Biochemistry 66(17):2072-2091.

75. Li Y, Kim JI, Pysh L, Chapple C (2015) Four Isoforms of Arabidopsis 4-Coumarate:CoA Ligase Have Overlapping yet Distinct Roles in Phenylpropanoid Metabolism. PLANT PHYSIOLOGY 169(4):2409-2421.

76. Lauvergeat V, et al. (2001) Two cinnamoyl-CoA reductase (CCR) genes from Arabidopsis thaliana are differentially expressed during development and in response to infection with pathogenic bacteria. The International Journal of Plant Biochemistry 57(7):1187-1195.

77. Baltas M, et al. (2005) Kinetic and inhibition studies of cinnamoyl-CoA reductase 1 from Arabidopsis thaliana. Plant Physiology et Biochemistry 43(8):746-753.

78. Sibout R, et al. (2005) CINNAMYL ALCOHOL DEHYDROGENASE-C and -D are the primary genes involved in lignin biosynthesis in the floral stem of Arabidopsis. THE PLANT CELL ONLINE 17(7):2059-2076.

79. Eudes A, et al. (2006) Evidence for a role of AtCAD 1 in lignification of elongating stems of Arabidopsis thaliana. Planta 225(1):23-39.

80. Franke R, et al. (2002) The Arabidopsis REF8 gene encodes the 3-hydroxylase of phenylpropanoid metabolism. Plant J 30(1):33-45.

81. Barros J, et al. (2019) 4-Coumarate 3-hydroxylase in the lignin biosynthesis pathway is a cytosolic ascorbate peroxidase. Nature Communications:1-11.

82. Do C-T, et al. (2007) Both caffeoyl Coenzyme A 3-O-methyltransferase 1 and caffeic acid O-methyltransferase 1 are involved in redundant functions for lignin, flavonoids and sinapoyl malate biosynthesis in Arabidopsis. Planta 226(5):1117-1129.

83. Hoffmann L, Maury S, Martz F, Geoffroy P, Legrand M (2003) Purification, cloning, and properties of an acyltransferase controlling shikimate and quinate ester intermediates in phenylpropanoid metabolism. $J$ Biol Chem 278(1):95-103.

84. Vanholme R, et al. (2013) Caffeoyl shikimate esterase (CSE) is an enzyme in the lignin biosynthetic pathway in Arabidopsis. Science 341(6150):1103-1106.

85. Nair RB, Bastress KL, Ruegger MO, Denault JW, Chapple C (2004) The Arabidopsis thaliana REDUCED EPIDERMAL FLUORESCENCE1 gene encodes an aldehyde dehydrogenase involved in ferulic acid and sinapic acid biosynthesis. THE PLANT CELL ONLINE 16(2):544-554.

86. Meyer K, Shirley AM, Cusumano JC, Bell-Lelong DA, Chapple C (1998) Lignin monomer composition is determined by the expression of a cytochrome P450-dependent monooxygenase in Arabidopsis. Proceedings of the National Academy of Sciences 95(12):6619-6623. 
A

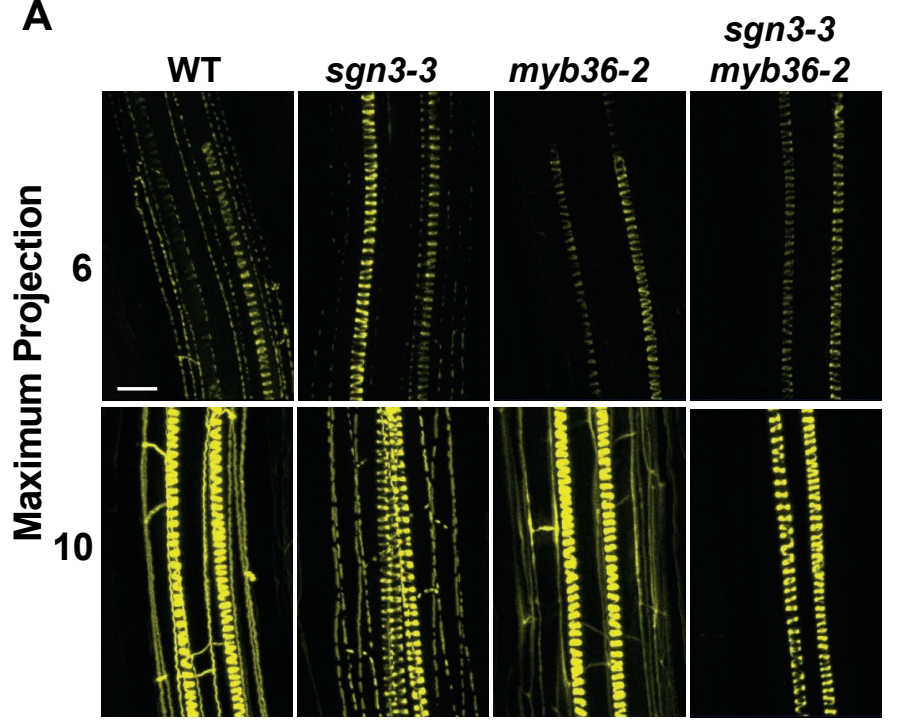

B

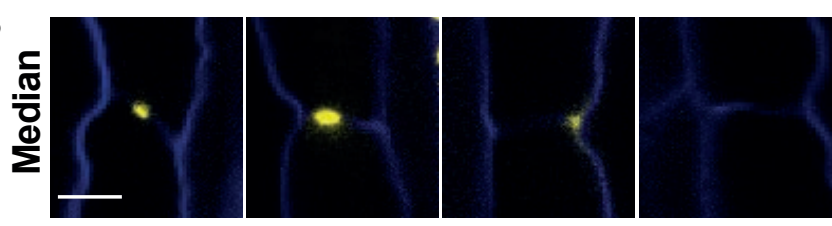

C

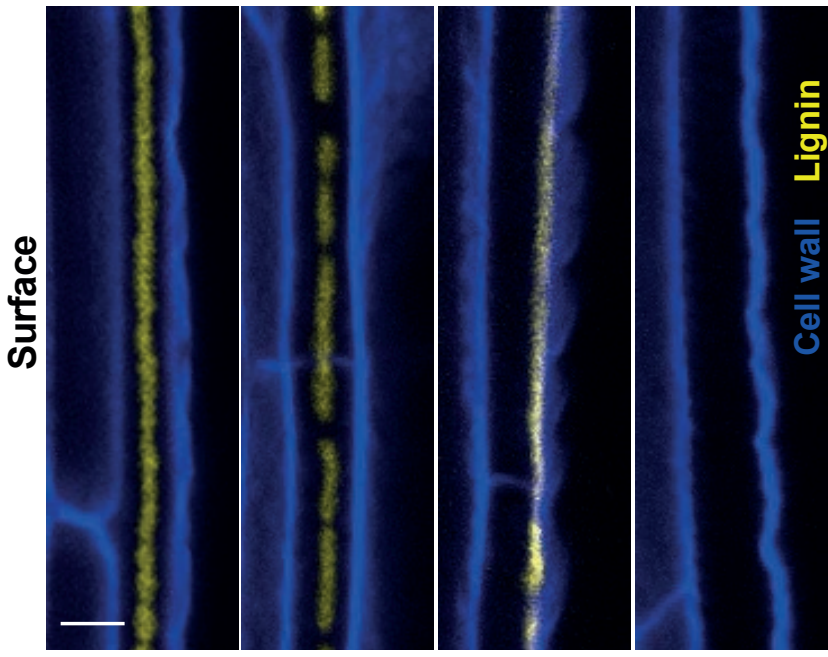

D
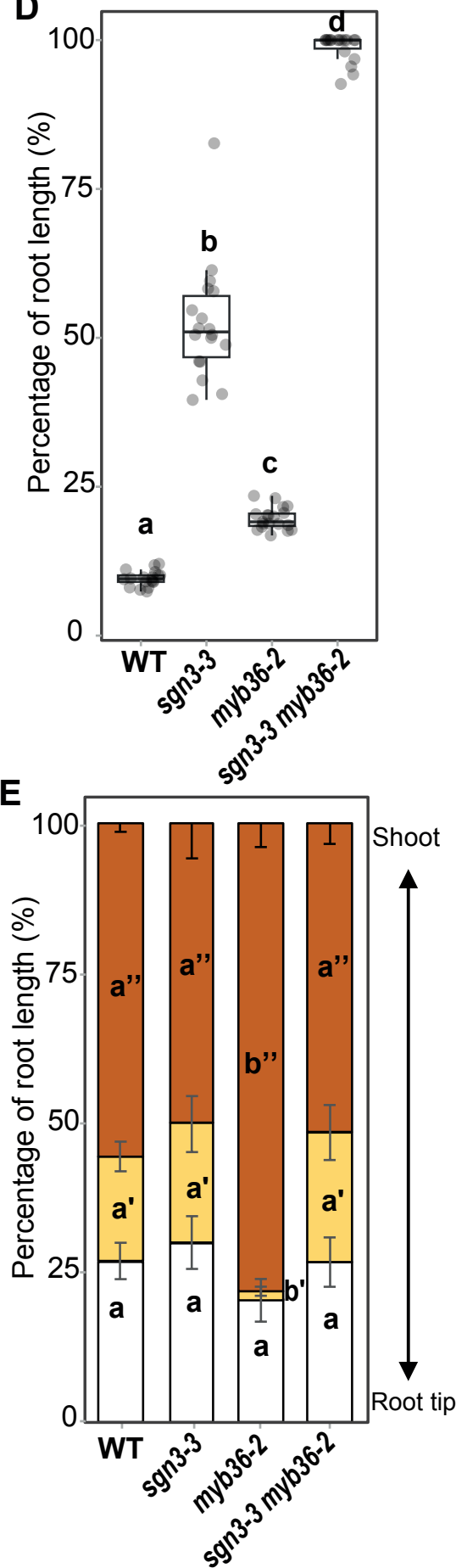

Figure 1. Disruption of $M Y B 36$ and $S G N 3$ abolish endodermal lignification and root apoplastic barrier.

(A) Maximum projection of lignin staining at the $6^{\text {th }}$ and $10^{\text {th }}$ endodermal cell after the onset of elongation. Spiral structures in the centre of the root are xylem. Scale bar $=10 \mu \mathrm{m}$. Median (B) and surface (C) view of an endodermal cell at 10 cells after the onset of elongation. Scale $\mathrm{bar}=5 \mu \mathrm{m}$. The roots were cleared and stained with basic fuchsin (yellow) for lignin and with Calcofluor white (blue) for cellulose. (D) Boxplot showing the percentage of the root length permeable to propidium iodide. $\mathrm{n}=18$ from two independent experiments. Different letters represent significant differences between genotypes using a Mann-Whitney test $(p<0.01)$. (E) Quantification of suberin staining along the root. The results are expressed in percentage of root length divided in three zones: unsuberised (white), discontinuously suberised (yellow), continuously suberised (orange). $\mathrm{n}=6$, error bars: SD. Individual letters show significant differences using a Mann-Whitney test between the same zones $(p<0.01)$. 
A
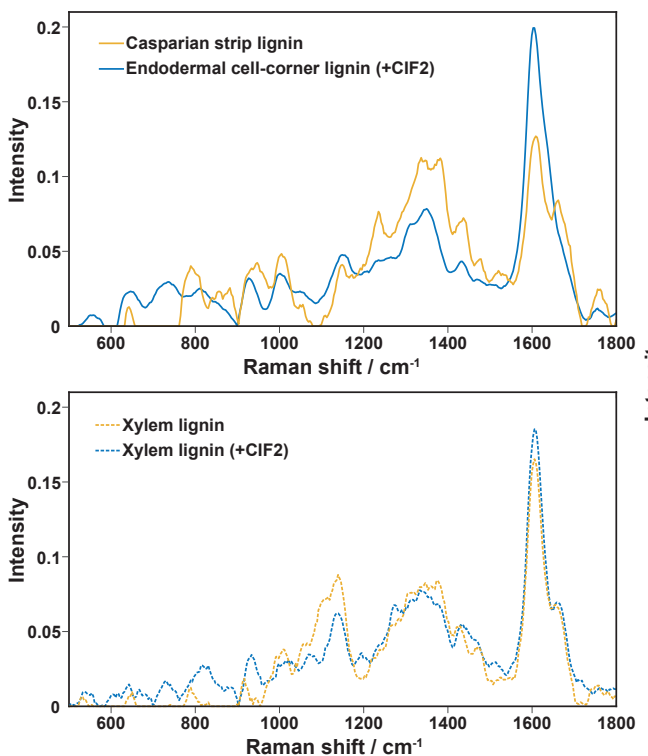

D

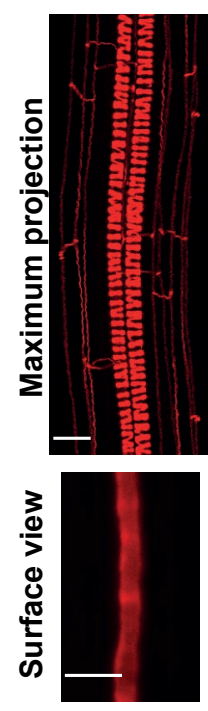

WT
B

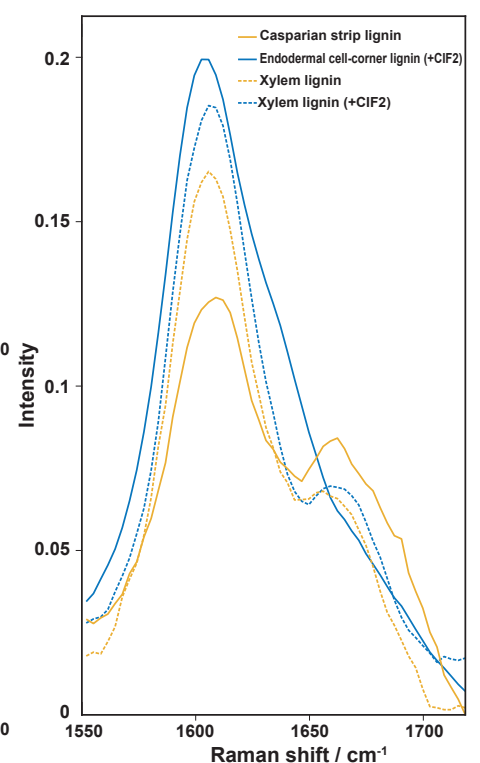

Raman shift $/ \mathrm{cm}^{-1}$
C

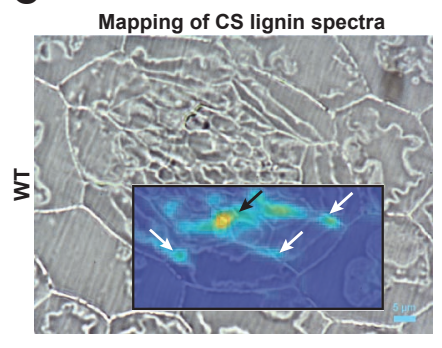

Mapping of endodermal cell-corner
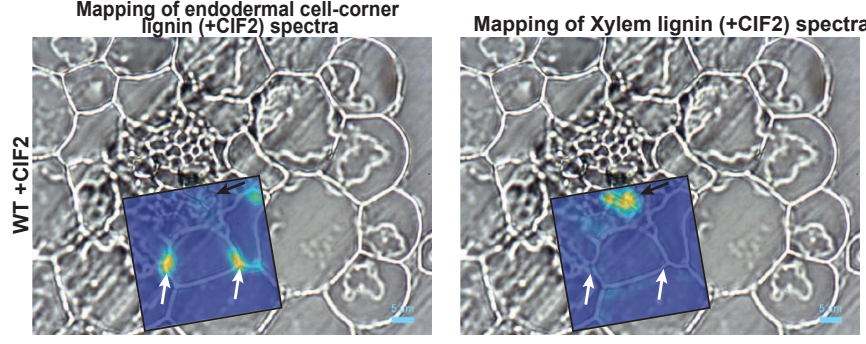

Low $\square$ High

Mapping of Xylem lignin spectra

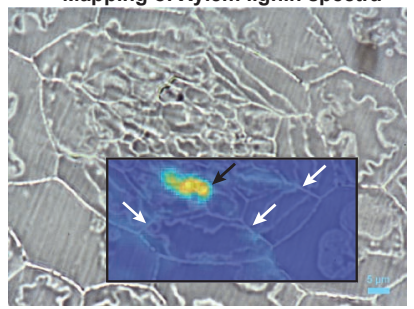

Mapping of Xylem lignin (+CIF2) spectra

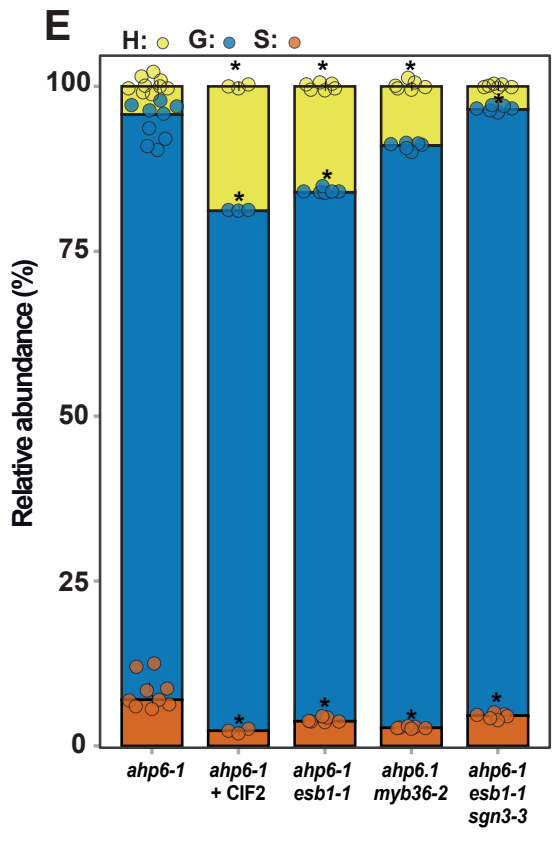

Figure 2. Activation of the Schengen-pathway triggers the deposition of a distinct "stress" lignin in the endodermis.

(A) Raman spectra of lignin of the different regions of interest presented in Sup. Fig. 1 and determined using a Multivariate Curve Resolution (MCR) analysis. The MCR analysis was performed on small Raman maps from independent plants containing CS lignin of WT ( $n=8)$, cell-corner lignin of WT treated with CIF2 $(+$ CIF2; $n=5)$ and for xylem lignin of WT $(n=2)$ and xylem lignin of WT treated with CIF2 $(n=2)$. (B) Close view of Raman spectra presented in (A) in the lignin aromatic region between $1550 \mathrm{~cm}^{-1}$ and $1700 \mathrm{~cm}^{-1}$. (C) Large Raman maps of roots of WT and WT treated with CIF2 (+CIF2). The intensity of the different lignin spectra presented in (A) was mapped onto large Raman maps containing xylem and endodermal lignin. (D) Lignin staining with basic fuchsin at a distance of $3 \mathrm{~mm}$ from the root tip in WT, ahp6-1, ahp6-1esb1-1, ahp6-1esb1-1sgn3-3, ahp6-1myb36-2 and ahp6-1 treated with CIF2. The plants were grown for 6 days in presence of $10 \mathrm{nM} 6$-Benzylaminopurine (BA). Upper panel shows a maximum projection of the root (Scale bar $=10 \mu \mathrm{m}$ ). Spiral structures in the centre only observed in the WT root are protoxylem. Lower panel shows surface view of endodermal cells (Scale bar $=5 \mu \mathrm{m}$ ). White arrows indicate ectopic lignification. (E) Relative abundance of the lignin monomers released by thioacidolysis ( $p$-hydroxyphenyl $(\mathrm{H})$, guaiacyl $(\mathrm{G})$, and syringyl (S) units) in root tips of ahp6-1 ( $\mathrm{n}=9)$, ahp6-1 treated with CIF2 (+CIF2; $\mathrm{n}=3)$, ahp6-1esb1-1 $\mathrm{n}=6$, ahp6-1 myb36-2 $(\mathrm{n}=6)$ and ahp6-1 esb1-1 sgn3-3 $(\mathrm{n}=6)$. Asterisks represent significant differences from the ahp6-1 control for each individual monomer using a Mann-Whitney U test $(p$-value $<0.01)$. 
bioRxiv preprint doi: $h t t p s: / / d o i . o r g / 10.1101 / 2020.10 .07 .329664$; this version posted October 8,2020 . The copyright holder for this preprint (which was not certified by peer review) is the author/funder, who has granted bioRxiv a license to display the preprint in perpetuity. It is made available under aCC-BY-NC-ND 4.0 International license.

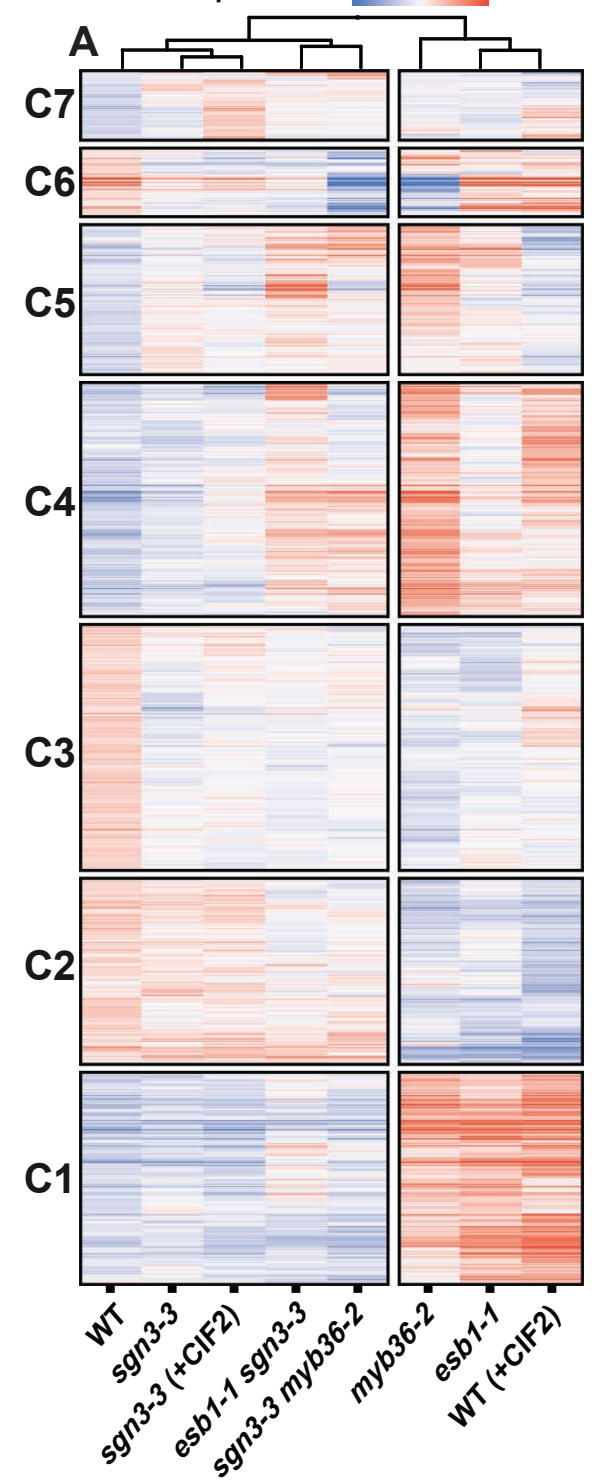

B

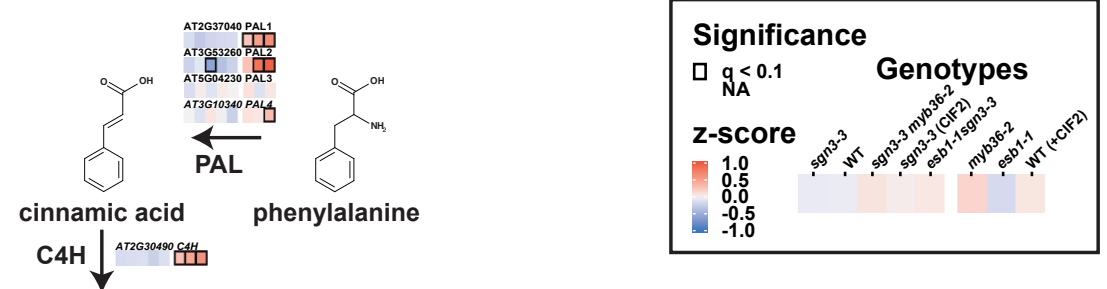

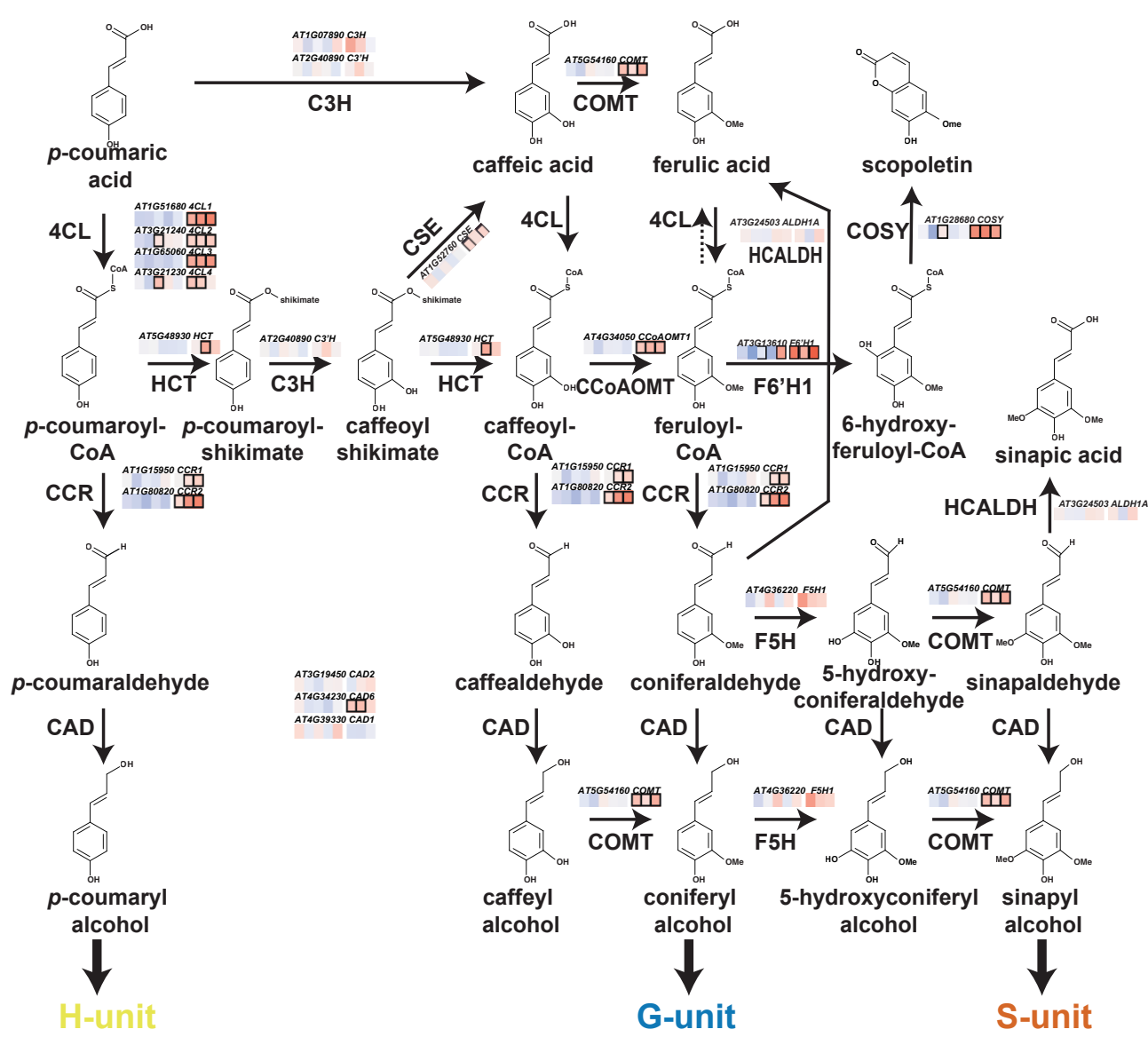

Figure 3. Modulation of the phenylpropanoid pathway by the Schengen-pathway.

(A) Heatmap of the 3266 differentially expressed genes identified in the RNA-seq in root tips of wild-type (WT), sgn3-3, esb1-1, myb36-2, esb1-1 sgn3-3, sgn3-3 myb36-2 plants. Treatment with $100 \mathrm{nM}$ CIF2 was applied as indicated (+CIF2) for WT and sgn3-3 plants. Clusters (C) are designated with numbers $(n=6)$. Genes belonging to each cluster are listed in Sup. Table 1. (B) Phenylpropanoid pathway leading to the lignin monomers and scopoletin biosynthesis (adapted from and (68)). Solid arrows represent enzymatic steps. Gene expression from the genes selected in Sup. Fig. 3C were mapped on the pathway according to their KEGG enzyme nomenclature. Only the genes with a demonstrated function in lignin biosynthesis as listed in Sup. Fig. 3C were mapped. PAL, PHENYLALANINE AMMONIA-LYASE; C4H, CINNAMATE 4-HYDROXYLASE; 4CL, 4-COUMARATE:CoA LIGASE; HCT, $p$ HYDROXYCINNAMOYL-CoA:QUINATE/SHIKIMATE $p$ HYDROXYCINNAMOYLTRANSFERASE; C'3H, $p$-COUMARATE 3'-HYDROXYLASE; C3H, COUMARATE 3-HYDROXYLASE; CSE, CAFFEOYL SHIKIMATE ESTERASE; CCoAOMT, CAFFEOYL-CoA O-METHYLTRANSFERASE; CCR, CINNAMOYL-CoA REDUCTASE; F5H, FERULATE 5-HYDROXYLASE; COMT, CAFFEIC ACID OMETHYLTRANSFERASE; CAD, CINNAMYL ALCOHOL DEHYDROGENASE; HCALDH, HYDROXYCINNAMALDEHYDE DEHYDROGENASE; COSY, COUMARIN SYNTHASE; F6'H1 FERULOYL COA ORTHO-HYDROXYLASE 1. 

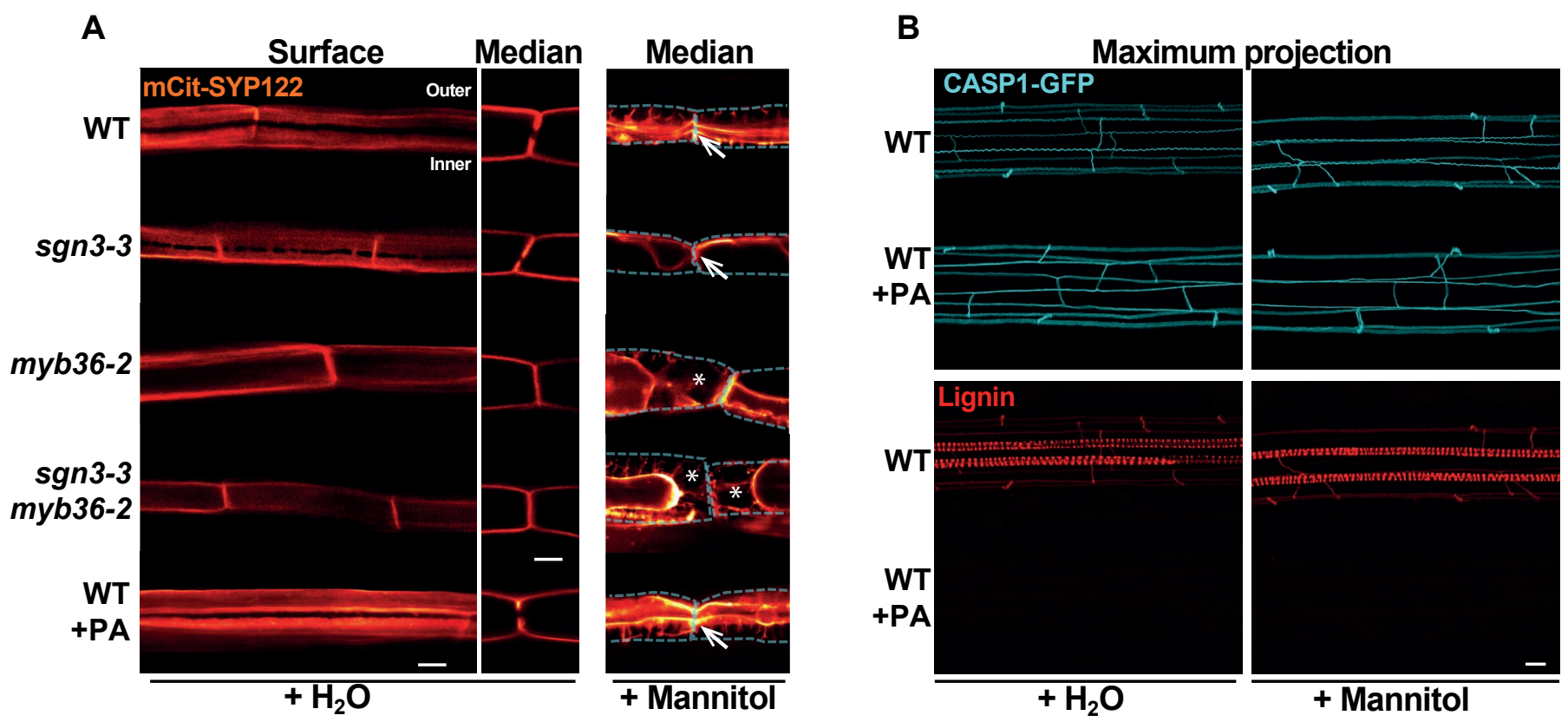

Supplemental Figure 4. Plasma membrane attachment to the cell wall.

(A) Maximum projection of the top endodermal cells as shown in the schematic view. The observations were done in lines expressing the plasma membrane marker line pELTP::SYP122mCitrine before plasmolysis $\left(+\mathrm{H}_{2} \mathrm{O}\right)$ and after plasmolysis (+Mannitol) at 15 cells after the onset of elongation. The dashed line represents the contours of the cells. Asterisks show the plasmolysis generated space where no attachment is observed. Scale bar $=5 \mu \mathrm{m}$. Representative pictures are shown. 
A

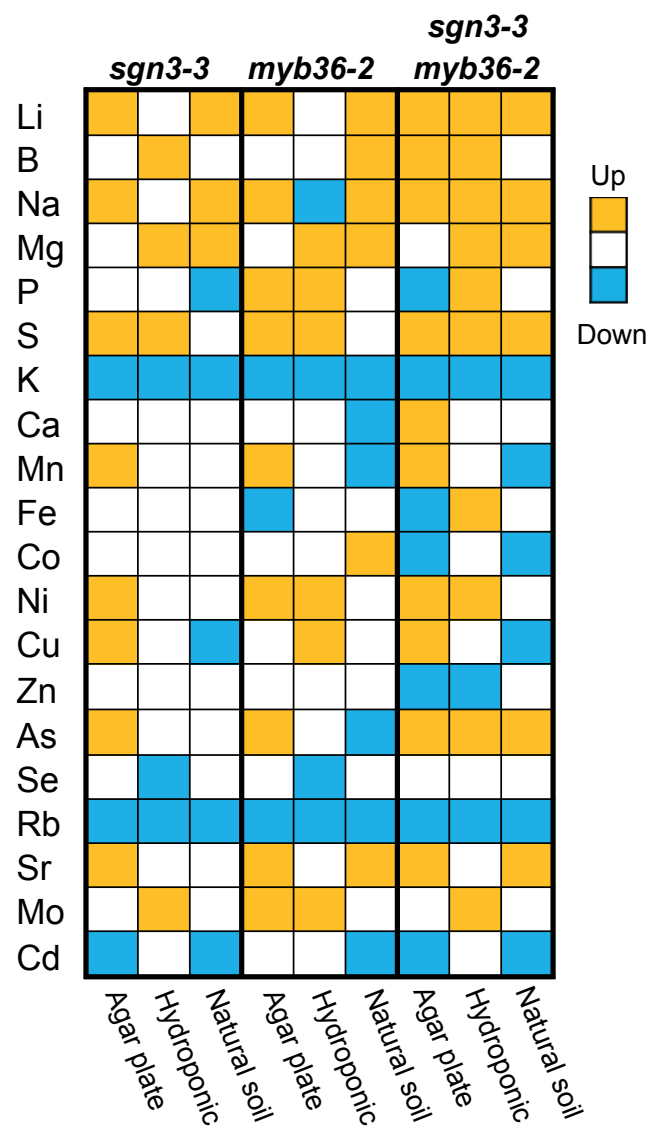

B

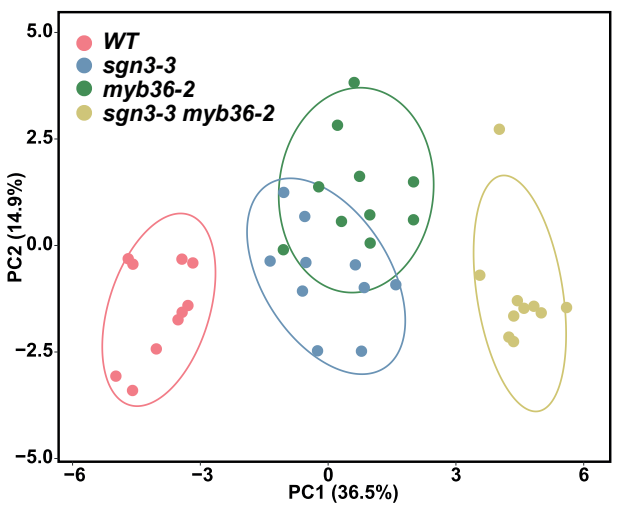

C

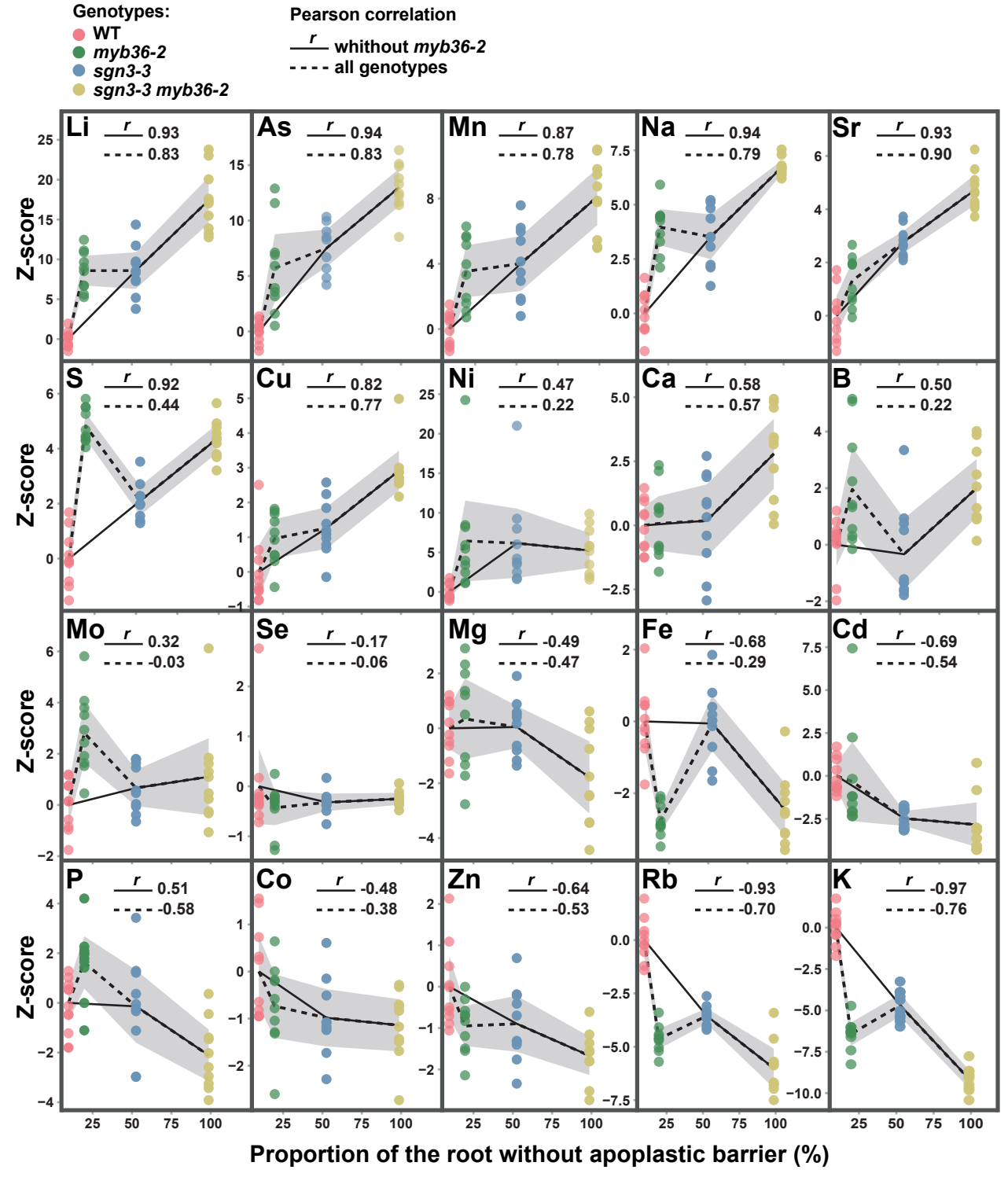

Figure 5. Absence of endodermal apoplastic barrier triggers major ionomic changes.

(A) Overview of ions accumulation in shoot of sgn3-3, myb36-2 and sgn3-3 myb36-2 mutants compared to WT using different growth conditions in agar plates (long day, $\mathrm{n}=10$ ), in hydroponics (short day, $n=6$ ) and natural soil (short day, $n \geq 13$ ). Elements concentration were determined by ICP-MS and are available in the Sup. Table 3. Colour code indicates significant changes in accumulation compared with the WT using a $t$ test $(\mathrm{p}<0.01)$. (B) Principal component analysis (PCA) based on the concentration of 20 elements in shoots of plants grown in agar plates. Ellipses show confidence level at a rate of $90 \% . n=10$ (C) Plots presenting the correlation between the z-scores of elements content in shoots of plants grown in agar plates of WT, myb36-2, sgn3-3 and sgn3-3 myb36-2 against the portion of root length permeable to propidium iodide as determined in Fig. 1D. The black lines show the average and the grey area show the $95 \%$ confidence interval $(n=10)$. 


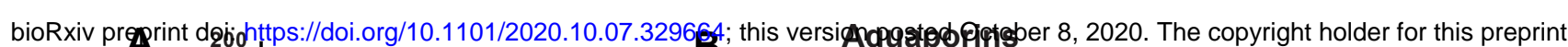

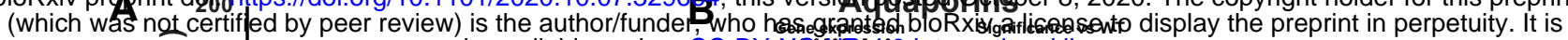
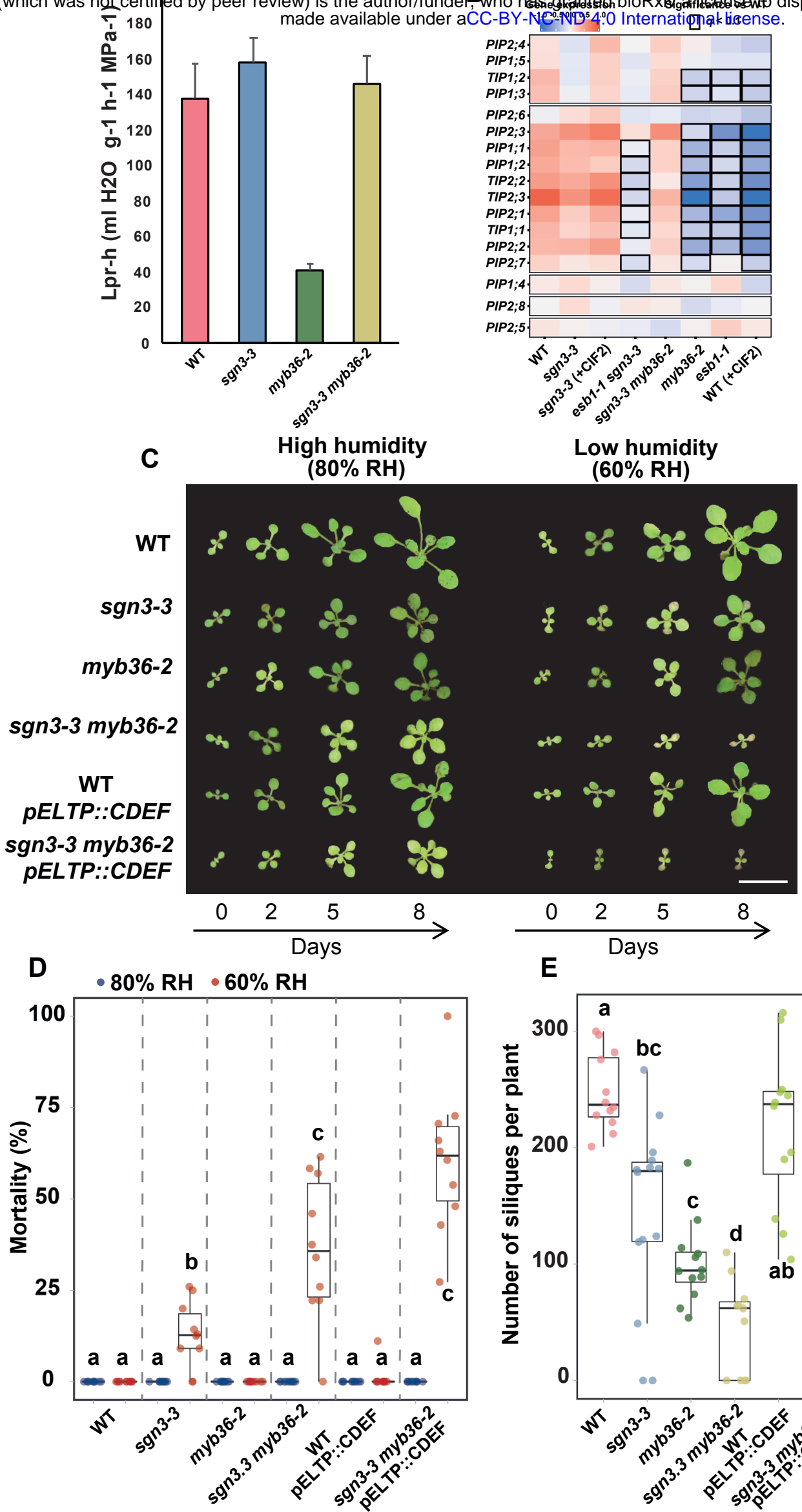

\section{Low humidity}

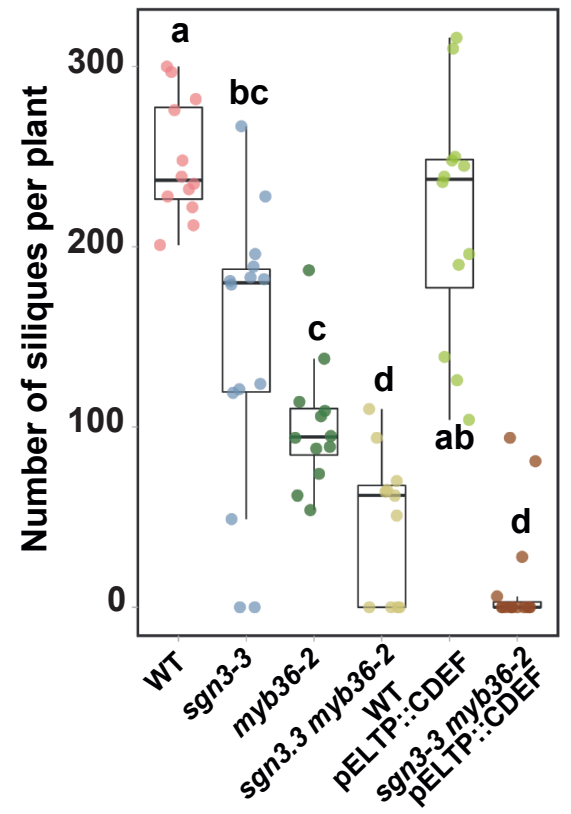

Figure 6. Activation of the Schengen-pathway represses water transport and maintains plant growth, survival and fitness under fluctuating environment

(A) Hydrostatic root hydraulic conductivity $\left(L \mathrm{p}_{\mathrm{r}-\mathrm{h}}\right)$ in WT, sgn3-3, myb36-2, sgn3-3 myb36-2 grown hydroponically for 19-21 days under environmental controlled conditions. Hydraulic conductivity was measured using pressure chambers $\left(L \mathrm{p}_{\mathrm{r}-\mathrm{h}}\right)$ (means $\pm \mathrm{SE}, \mathrm{n} \geq 3$ ). (B) Heatmap of aquaporins expression across the different genotypes and treatments used in the RNAseq experiment. (C) Representative pictures of WT, sgn3-3, myb36-2, sgn3-3 myb36-2, WT - pELTP::CDEF and sgn3-3 myb36-2 - pELTP::CDEF plants germinated in soil with a high humidity (80\%) for 7 days and then transferred in an environment with a lower $(60 \% \mathrm{RH})$ or with constant humidity $(80 \% \mathrm{RH})$. Pictures were taken $0,2,5$ and 8 days after the transfer. Scale bar $=1 \mathrm{~cm}$. (D) Boxplots showing the proportion of dead plants after transfer in an environment with constant humidity $(80 \% \mathrm{RH}$, blue) or with a lower $(60 \% \mathrm{RH}$, red). The plants displaying no growth after 9 days and showing necrosis in all the leave surface were considered as dead plants. Each point represents the proportion of dead plants in a cultivated pot compared to the total number of plants for one genotype in the same pot. Pots were containing at least 8 plants of each genotypes, $\mathrm{n}=10$ pots. Different letters represent significant differences between genotypes using a Mann-Whitney test $(\mathrm{p}<0.01)$. (E) Boxplots showing the number of siliques produced per plants. Plants were cultivated in a high humidity environment for 10 days after germination and then transferred to a greenhouse. Each point represents the total number of seeds containing siliques per plant ( $\mathrm{n} \geq 12)$. Different letters represent significant differences between genotypes using a Mann-Whitney test $(\mathrm{p}<0.01)$. 
bioRxiv preprint doi: https://doi.org/10.1101/2020.10.07 329664; this version posted October 8,2020 . The copyright holder for this preprint (which was not certified by peer review) is the author/funder, who has granted bioRxiv a license to display the preprint in perpetuity. It is made available under aCC-BY-NC-ND 4.0 International license.

Endodermis

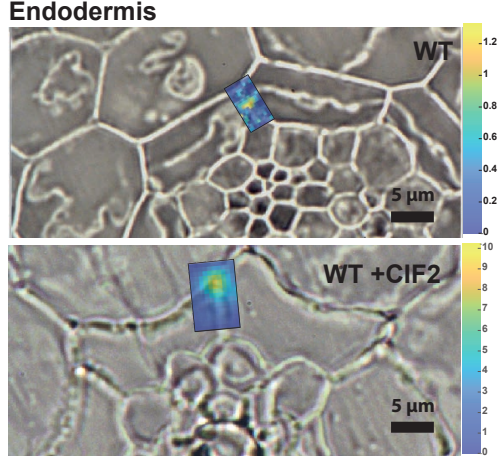

Xylem

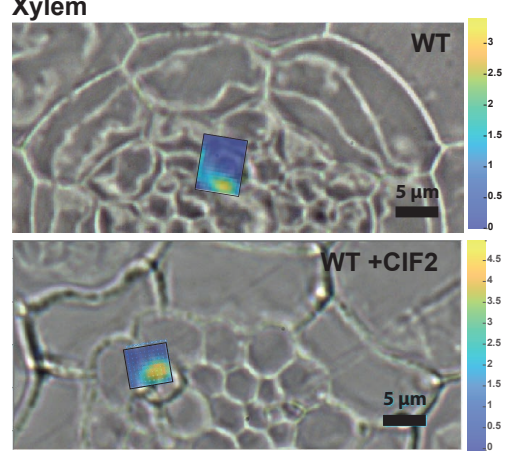

Supplemental Figure 1. Activation of the Schengen-pathway triggers the deposition of a distinct "stress" lignin in the endodermis.

Examples of small Raman maps for endodermal cells of WT(Ø) and WT(+CIF2) and for xylem of WT(Ø) and WT(+CIF2) used for determining the lignin spectra using Multivariate Curve Resolution (MCR) presented in Fig. 2 C-D. The colour code represents the intensity of the lignin factor presented in Fig. 2 C-D. 
bioRxiv preprint doi: https://doi.org/10.1101/2020.10.07.329664; this version posted October 8, 2020. The copyright holder for this preprint (which was not certified by peer review) is the author/funder, who has granted bioRxiv a license to display the preprint in perpetuity. It is made available under aCC-BY-NC-ND 4.0 International license.

A

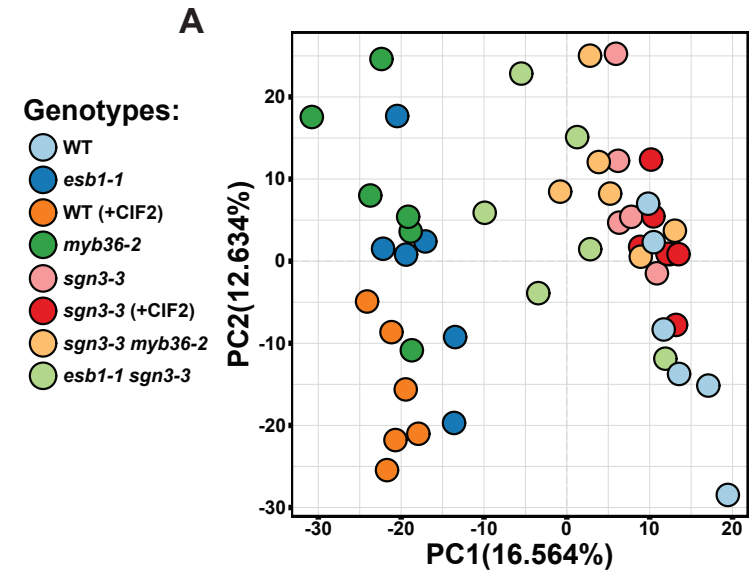

\section{B}

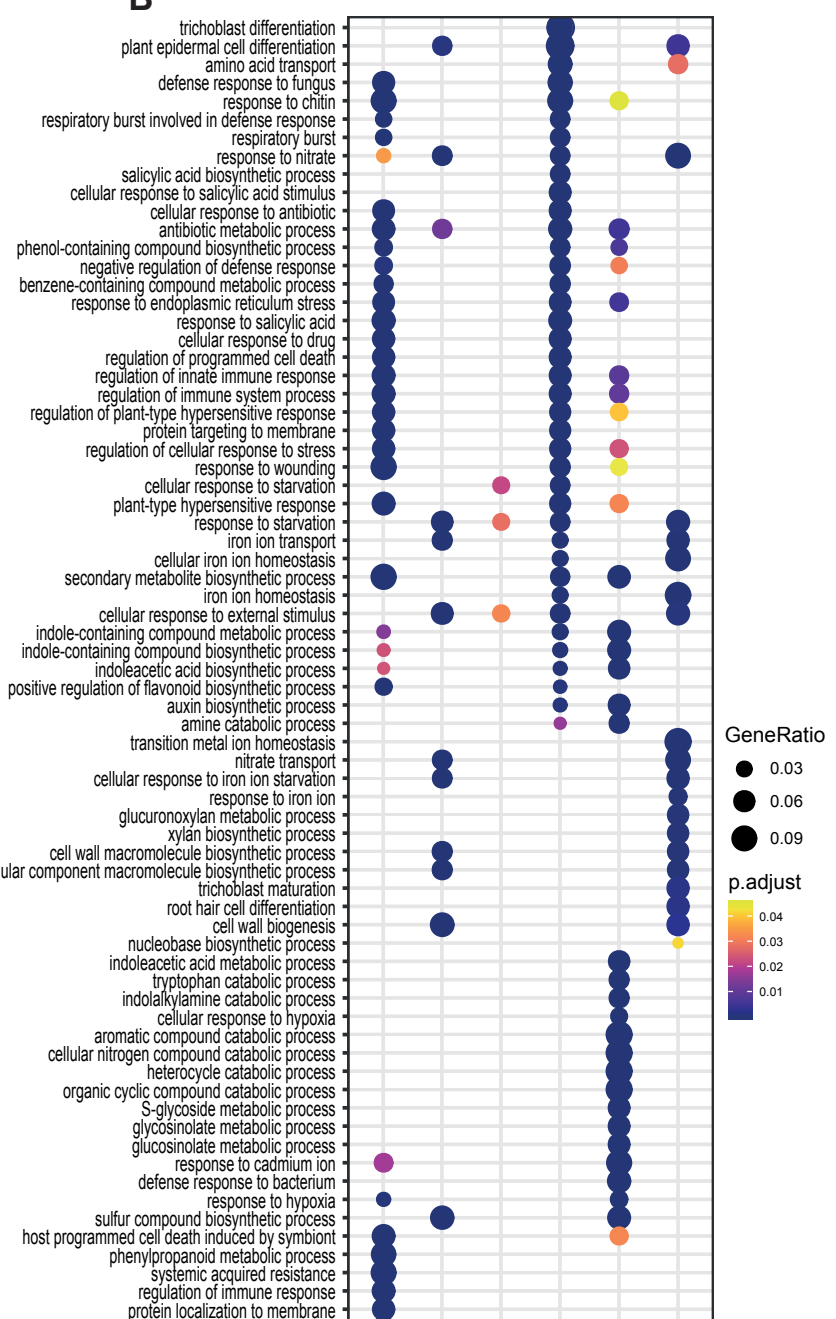

Phenylpropanoid pathway

C
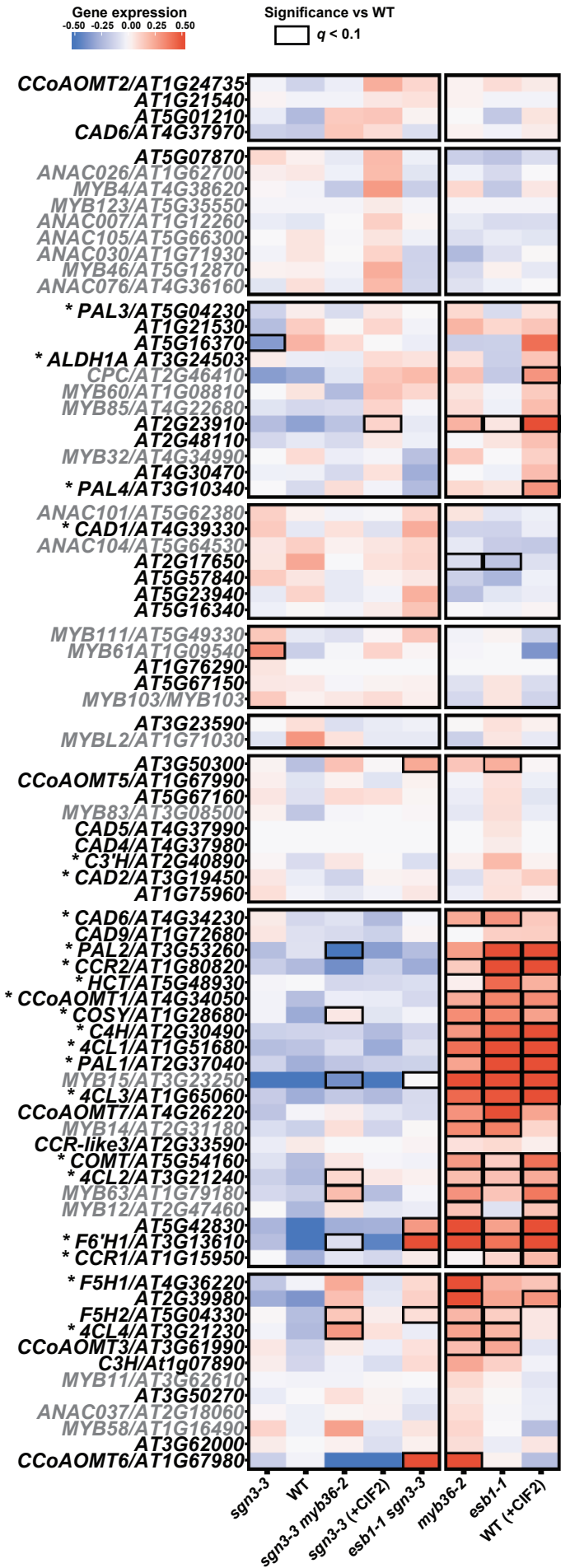

Supplemental Figure 2. Gene expression profiling in response to the activation of the Schengen-pathway.

(A) Principal component analysis (PCA) of the differentially expressed genes identified in root tips of wild-type (WT), sgn3-3, esb1-1, myb36-2, esb1-1 sgn3-3, sgn3-3 myb36-2 plants. Treatment with $100 \mathrm{nM}$ CIF2 was applied as indicated $(+\mathrm{CIF} 2)$ for WT and sgn3-3 plants ( $\mathrm{n}=$ 6). (B) Gene ontology enrichment in the different gene clusters from Fig. 3A. The colour of each point represents the p-value adjusted using the Benjamin-Hochberg procedure, and the size of each point denotes the percentage of total differential expressed genes in the given gene ontology term (Gene Ratio). (C) Heatmap of gene expression of genes related to the phenylpropanoid pathway (black) (69) and their transcriptional regulators (grey) $(43,70)$. Genes names are given according to (71) for genes related to the phenylpropanoid pathway. Asterisks indicate demonstrated function in lignin biosynthesis with an activity demonstrated in vitro or in vivo according to (72) for PAL1-4, to for $(73) C 4 H,(74,75)$ for $4 C L 1-4,(76,77)$ for $C C R 1$ and $2,(78,79)$ for $C A D 1,2$ and $6,(80)$ for $C 3^{\prime} H,(81)$ for $C 3 H,(82)$ for $C O M T$ and CCoAOMT1, (83) for HCT, (84) for CSE, (85) for ALDH1A, (45) for F6' $H 1$, (46) for COSY and (86) for $F 5 H 1$. 
bioRxiv preprint doi: https://doi. org/10.1101/2020.10.07.329664; this version posted October 8, 2020. The copyright holder for this preprint (which was not certified by peer review) is the author/funder, who has granted bioRxiv a license to display the preprint in perpetuity. It is made available under aCC-BY-NC-ND 4.0 International license.

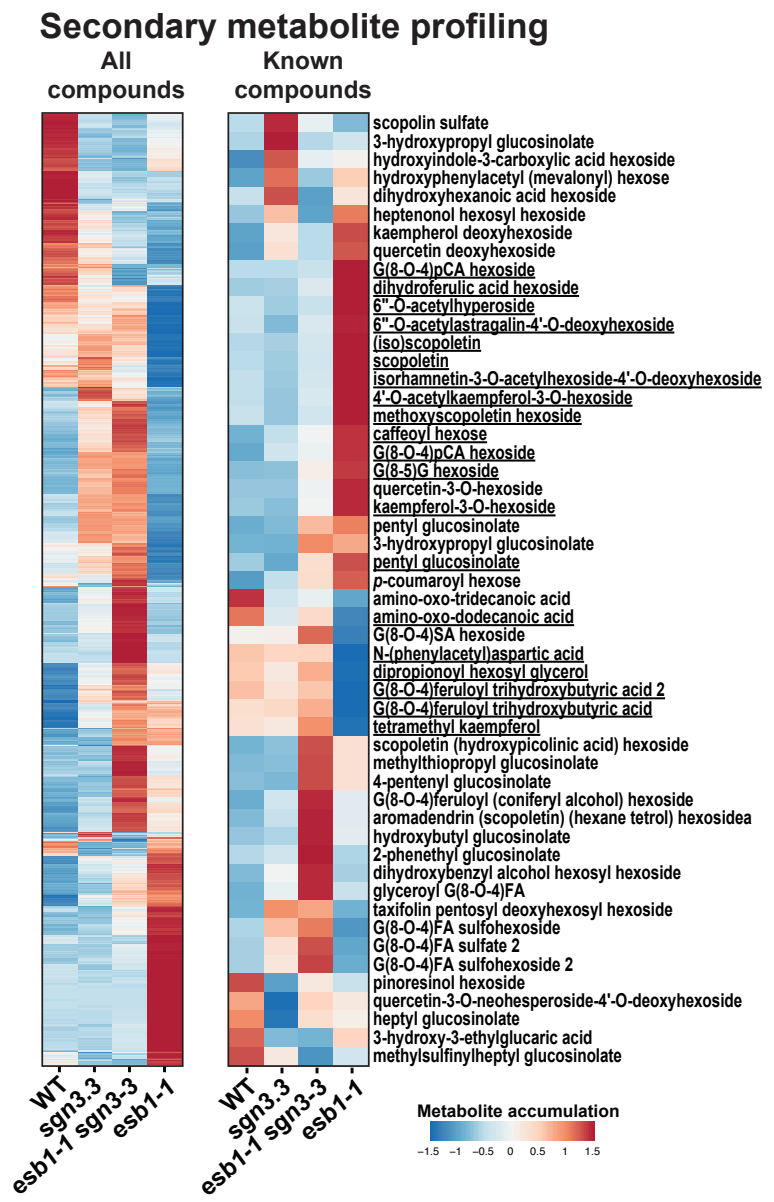

Supplemental Figure 3. Metabolite profiling in response to the activation of the Schengenpathway.

Heatmaps of metabolite profiling determined using Ultra High Performance Liquid Chromatography (UHPLC) in $5 \mathrm{~mm}$ roots tips of wild-type (WT), sgn3-3, esb1-1 sgn3-3 and esb1-1. The heatmaps show all the compounds (2497, left) and characterised compounds (52, right) that are differentially accumulated ( $q$-value $<0.01$, left; $q$-value $<0.1$, right $\mathrm{n}=8$ ). Underlined names are for compounds that are only differentially accumulated (q-value $<0.1$ ) in esb1-1 and not changed in sgn3-3 and esb1-1 sgn3-3 in comparison with WT. Data for the known compounds are presented in Sup. Table 3. 
bioRxiv preprint doi: https://doi org/10.1101/2020 10.07.329664; this version posted October 8, 2020. The copyright holder for this preprint (which was not certified by peer review) is the author/funder, who has granted bioRxiv a license to display the preprint in perpetuity. It is made available under aCC-BY-NC-ND 4.0 International license.

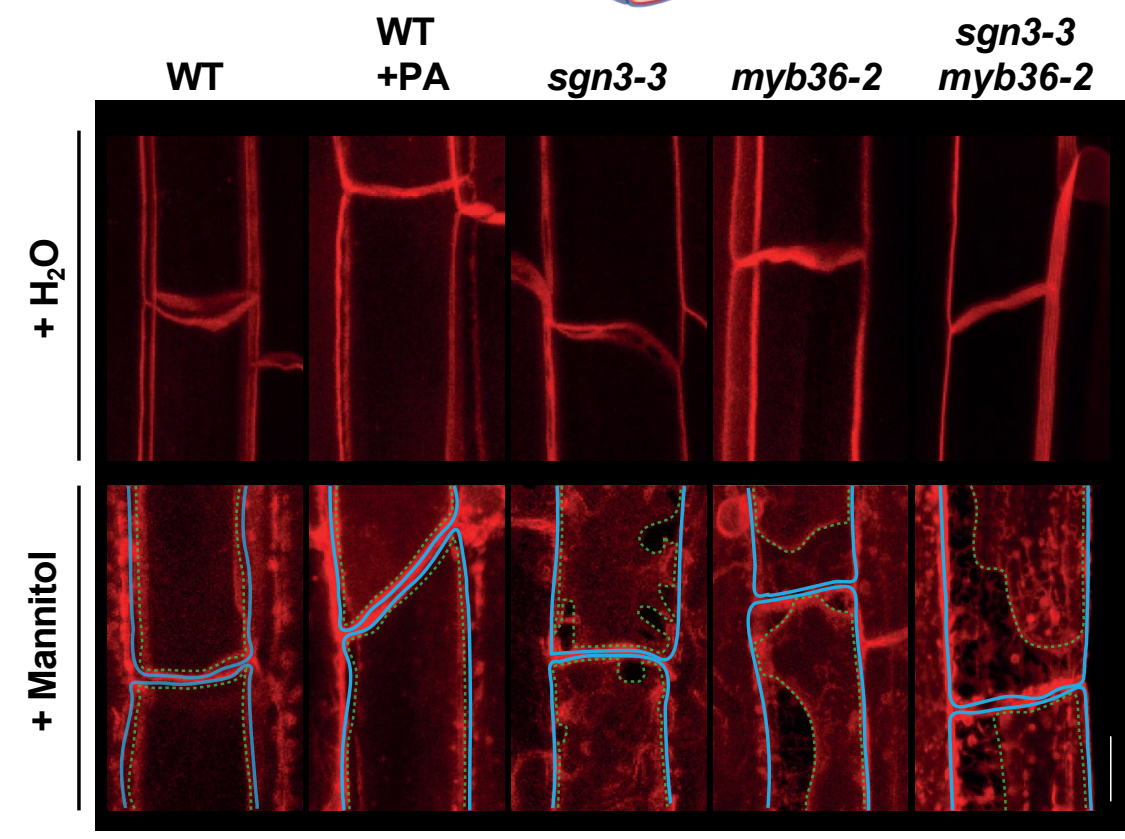

Supplemental Figure 4. Plasma membrane attachment to the cell wall.

(A) Maximum projection of the top endodermal cells as shown in the schematic view. The observations were done in lines expressing the plasma membrane marker line pELTP::SYP122mCitrine before plasmolysis $\left(+\mathrm{H}_{2} \mathrm{O}\right)$ and after plasmolysis (+Mannitol) at 15 cells after the onset of elongation. The dashed line represents the contours of the cells. Asterisks show the plasmolysis generated space where no attachment is observed. Scale bar $=5 \mu \mathrm{m}$. Representative pictures are shown. 
bioRxiv preprint doi: https://doi.org/10.1101/2020.10.07.329664; this version posted October 8, 2020. The copyright holder for this preprint (which was not certified by peer review) is the author/funder, who has granted bioRxiv a license to display the preprint in perpetuity. It is

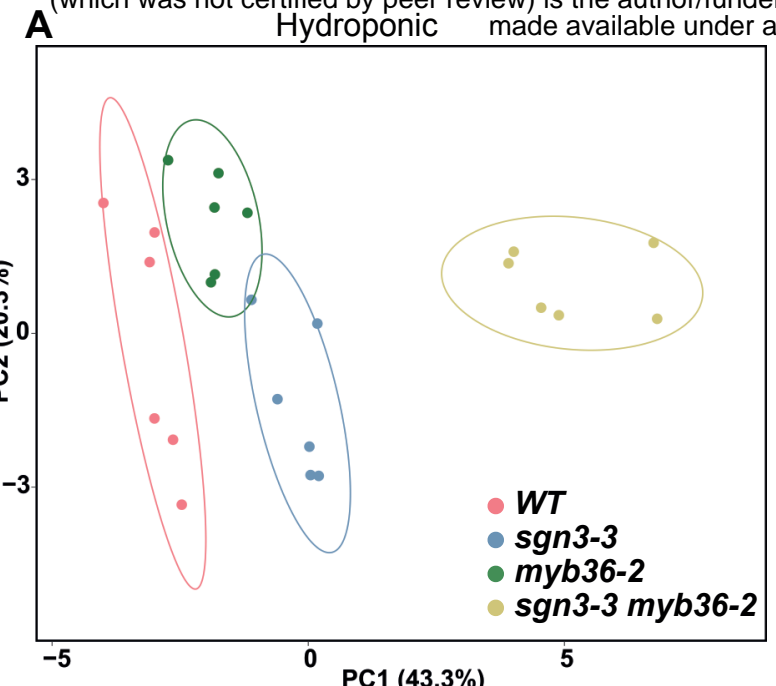

C

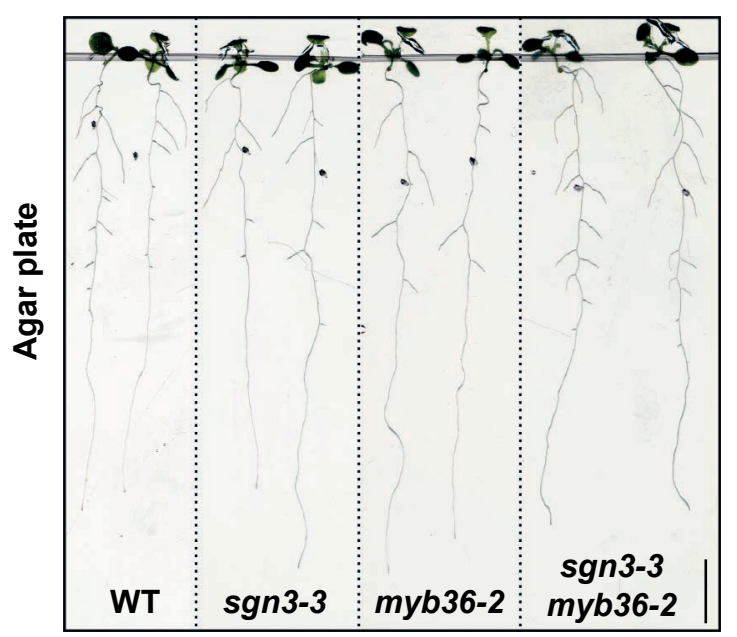

D

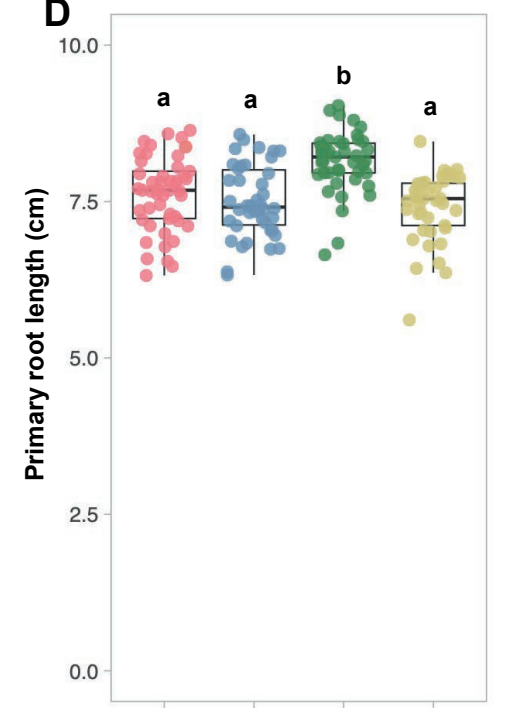

WT sgn3-3 myb36-2 sgn3-3

myb36-2

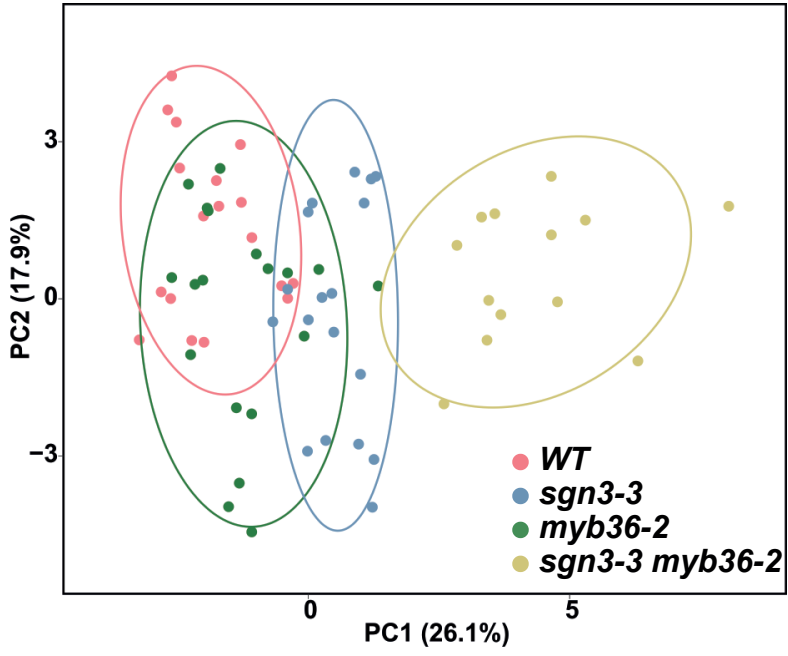

E

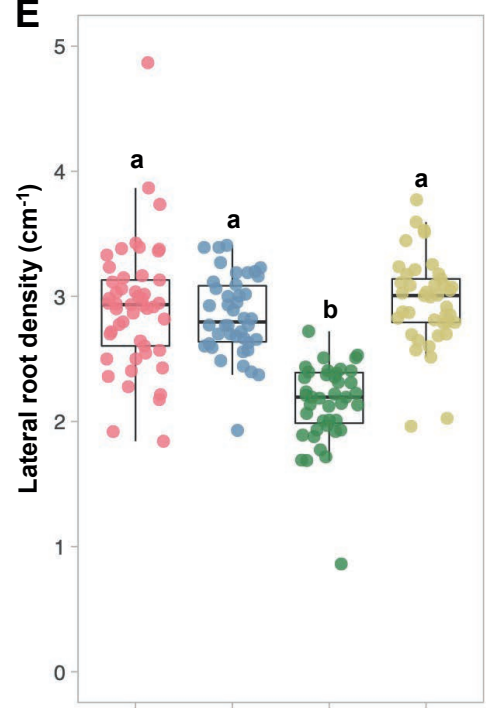

WT sgn3-3 myb36-2 sgn3-3

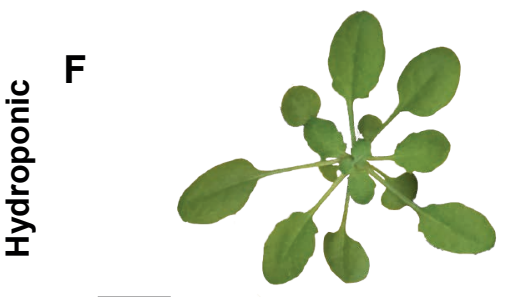

WT

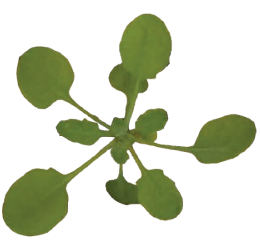

sgn3-3

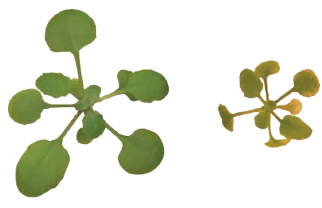

sgn3-3

myb36-2

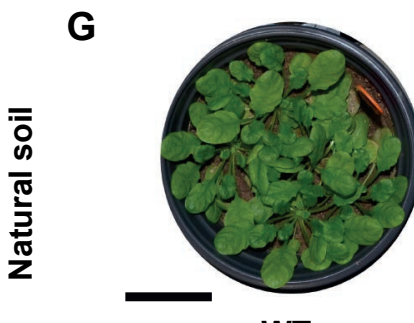

WT

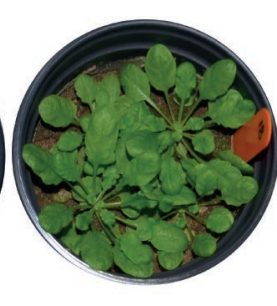

sgn3-3

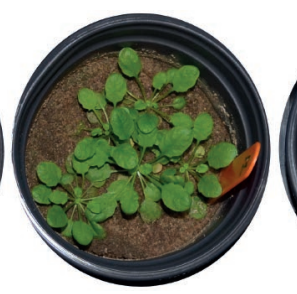

myb36-2

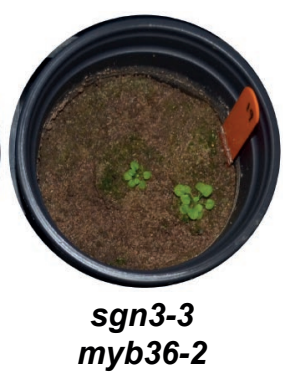

Supplemental Figure 5. Absence of endodermal apoplastic barrier triggers major ionomic changes in different growth conditions.

Principal component analysis (PCA) based on the concentration of 20 elements in shoots of WT, sgn3-3, myb36.3 and sgn3-3 myb36-2 plants grown in (A) hydroponics (short day, $\mathrm{n}=6$ ) and (B) natural soil (short day, $\mathrm{n} \geq 13$ ). Ellipses show confidence level at a rate of $90 \%$. (C) Pictures of 2-week-old wild-type (WT), sgn3-3, myb36-2 and sgn3-3 myb36-2 plants grown in agar plates. (D-E) Boxplots showing the primary root length (D) and lateral roots density (E) of 2-week-old WT, sgn3-3, myb36-2 and sgn3-3 myb36-2 plants grown in agar plates. Letters show significantly different groups according to a Tukey's test as post hoc analyses $(\mathrm{n} \geq 41$, $\mathrm{P}<0.01$ ). (F) Pictures of 5-week-old WT, sgn3-3, myb36-2 and sgn3-3 myb36-2 plants grown in hydroponics. Scale bar $=1 \mathrm{~cm}$. (G) Pictures of 9-week-old WT, sgn3-3, myb36-2 and sgn33 myb36-2 plants grown in natural soil. Scale bar $=3 \mathrm{~cm}$. 


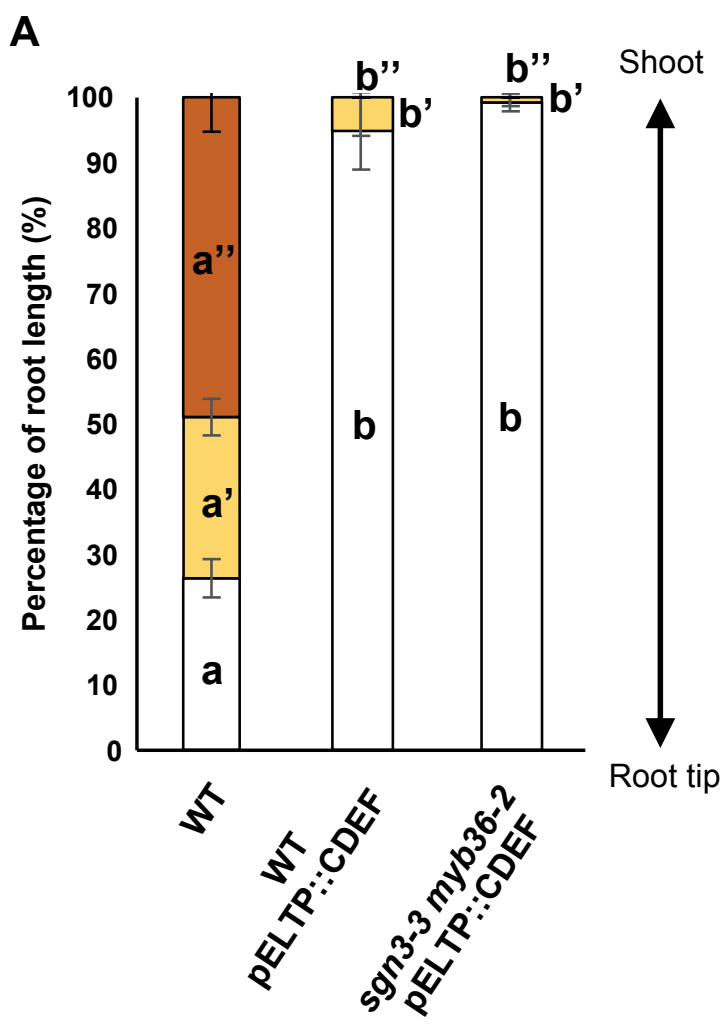

B

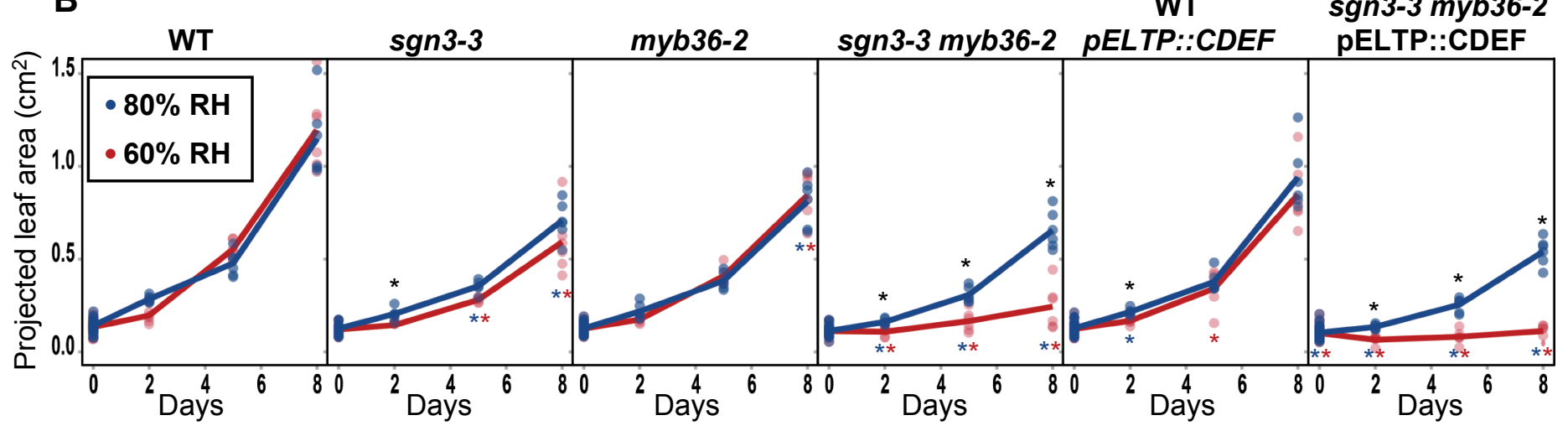

Supplemental Figure 6. Activation of the Schengen-pathway maintains plant growth under fluctuating environment.

(A) Quantification of suberin staining along the root of 6 days-old plants. The results are expressed in percentage of root length divided in three zones: unsuberised (white), discontinuously suberised (yellow), continuously suberised (orange). $\mathrm{n}=7$, error bars: SD. Individual letters show significant differences using a Mann-Whitney test between the same zones (p<0.01). (B) Graphs showing leaf surface area of WT, sgn3-3, myb36-2, sgn3-3 myb362, WT-pELTP::CDEF and sgn3-3 myb36-2-pELTP::CDEF plants germinated in soil with a high humidity $(80 \%)$ for 7 days and then transferred in an environment with constant $(80 \%$ $\mathrm{RH}$, blue) or with a lower humidity $(60 \% \mathrm{RH}$, red). Data were collected $0,2,5$ and 8 days after the transfer. Each point is the average leave surface per plant from a singles pot ( $\mathrm{n} \geq 6$ pots). Each pot contained at least 6 plants for each genotype. The line shows the average value for each measured time points. Black asterisk indicates a significant difference between high and low humidity for a same genotype at one time point. Blue and red asterisk indicate a significant difference in comparison with WT at the same time point respectively for the high and low humidity environment. The significant differences were calculated using a Tukey's test as post hoc analyses $(p<0.01)$. 